\title{
Kinetic Analysis of a Molecular Model of the Budding Yeast Cell Cycle
}

\author{
Katherine C. Chen, ${ }^{*}$ Attila Csikasz-Nagy, ${ }^{+}$Bela Gyorffy, ${ }^{+}$John Val, ${ }^{*}$ \\ Bela Novak, ${ }^{+}$and John J. Tyson ${ }^{* \ddagger}$
}

\author{
*Department of Biology, Virginia Polytechnic Institute and State University, Blacksburg Virginia \\ 24061; and 'Department of Agricultural Chemical Technology, Technical University of Budapest, \\ Gellert Ter 4, H-1521 Budapest, Hungary
}

Submitted May 6, 1999; Revised October 20, 1999; Accepted October 25, 1999

Monitoring Editor: Mark J. Solomon

\begin{abstract}
The molecular machinery of cell cycle control is known in more detail for budding yeast, Saccharomyces cerevisiae, than for any other eukaryotic organism. In recent years, many elegant experiments on budding yeast have dissected the roles of cyclin molecules $(\mathrm{Cln} 1-3$ and $\mathrm{Clb} 1-6)$ in coordinating the events of DNA synthesis, bud emergence, spindle formation, nuclear division, and cell separation. These experimental clues suggest a mechanism for the principal molecular interactions controlling cyclin synthesis and degradation. Using standard techniques of biochemical kinetics, we convert the mechanism into a set of differential equations, which describe the time courses of three major classes of cyclin-dependent kinase activities. Model in hand, we examine the molecular events controlling "Start" (the commitment step to a new round of chromosome replication, bud formation, and mitosis) and "Finish" (the transition from metaphase to anaphase, when sister chromatids are pulled apart and the bud separates from the mother cell) in wild-type cells and 50 mutants. The model accounts for many details of the physiology, biochemistry, and genetics of cell cycle control in budding yeast.
\end{abstract}

\section{INTRODUCTION}

To reproduce itself, a cell must duplicate all its components and separate them, more or less evenly, to two daughter cells, so that each daughter has the information and machinery necessary to repeat the process (Murray and Hunt, 1993; Alberts et al., 1994, chap. 17). In general, eukaryotic cells replicate and partition their genetic material in two distinct, coordinated processes. During S phase, the DNA molecule in each chromosome is precisely replicated to form two identical sister chromatids that are held together by cohesins (tethering proteins). During $\mathrm{M}$ phase, the cell builds a mitotic spindle, condenses its replicated chromosomes, aligns them on the midplane of the spindle, and then, at anaphase, removes the cohesins and separates sister chromatids to opposite poles of the spindle (Biggins and Murray, 1998; Zachariae and Nasmyth, 1999). Shortly after anaphase, the cell divides into two daughter cells, each one containing a complete set of chromosomes. $\mathrm{S}$ and $\mathrm{M}$ phases are usually separated temporally by gaps (G1 and G2 phases).

It is crucial that each DNA molecule be replicated once and only once per cycle in eukaryotes. Were this not the

\footnotetext{
‡ Corresponding author. E-mail address: tyson@vt.edu. Abbreviations: APC, anaphase-promoting complex; CDK, cyclin-dependent kinase.
}

case, then each chromosome would contain multiple sister chromatids, and segregation of the correct balance of DNA molecules to the spindle poles would be a difficult affair. This requirement is imposed by a set of proteins called licensing factors (Mcm2-7 and Cdc6). In the gap between the end of mitosis and the beginning of $S$ phase, licensing factors bind to and prime the origins of replication. At the G1/S boundary, several cyclin-dependent protein kinases (CDKs) become active and initiate replication at licensed origins. In the process, the CDKs apparently incapacitate the license at each origin that fires. As long as CDKs remain active, throughout S, G2, and M, licensing factors remain incapacitated, and rereplication is impossible (Botchan, 1996; Wuarin and Nurse, 1996; Leatherwood, 1998).

It is also crucial that the cell does not commence anaphase (sister chromatid separation) until DNA replication is complete and each pair of sister chromatids is properly aligned on the metaphase plate. Completion of DNA synthesis is usually a requirement for entry into $\mathrm{M}$ phase, whereas chromosome alignment is required for activation of the anaphase-promoting complex (APC) that initiates degradation of an inhibitor of sister chromatid separation (Amon, 1999; Nasmyth, 1999). At anaphase, the APC also mediates proteolysis of mitotic cyclins, thereby destroying CDK activities and allowing licensing factors to accumulate and origins to be primed for replication. 


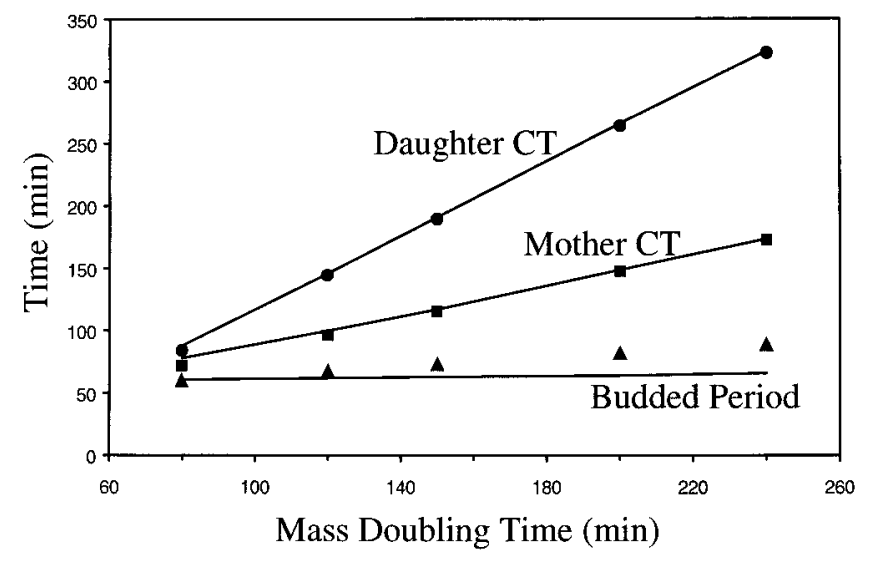

Figure 1. Mother and daughter cycle times (CT) as functions of the mass-doubling time of a culture. Lines, model simulations, calculated from the differential equations and parameter values in Tables 1 and 2. Symbols, experimental results from Lord and Wheals (1980): interdivision times of mothers $(\boldsymbol{\square})$ and daughters (O) and intervals from bud emergence to division $(\boldsymbol{A})$.

Third, the cell must coordinate its DNA replication-segregation cycle to cell growth, to maintain cell size within certain bounds, generation after generation. To achieve balanced growth and division, it is likely that some essential step in the cell cycle depends on the cell growing to a critical mass (Carter, 1981; Polymenis and Schmidt, 1999).

Although most eukaryotic cells satisfy these three requirements of DNA replication and division, there are notable exceptions, such as the cell cycles that produce oocytes, embryonic blastulas, and megakaryocytes. Furthermore, there are many variations in specific details from one cell type to another. For instance, budding yeast cells are peculiar in that they divide asymmetrically (Hartwell and Unger, 1977; Lord and Wheals, 1980). At Start, a bud emerges from the mother cell, and subsequent cytoplasmic growth is directed primarily to the bud. $S$ and $M$ phases are completed before the bud grows as large as its progenitor; thus cell separation produces a large mother cell and a small daughter cell. Shortly after division, the mother cell produces a new bud, but the daughter cell enters an extended G1 phase, during which it apparently must grow to a critical size before it can make a bud of its own. The whole process is quite sensitive to growth rate. At the fastest growth rates, division is almost symmetrical, and daughter cells have a short G1 phase as well. As growth rate is decreased, cell division becomes increasingly asymmetrical, and the G1 period of the daughter cell lengthens dramatically, whereas that of the mother cell remains relatively constant (Figure 1).

Another peculiarity of budding yeast is that cells progress simultaneously through $\mathrm{S}$ and $\mathrm{M}$ phases (DNA synthesis, spindle formation, and chromosome alignment), without any noticeable condensation of chromosomes. In this case, completion of DNA synthesis is not required for the early events of $M$ phase but is required for the metaphase-anaphase transition (Nasmyth, 1995).

Nasmyth (1996) has proposed that the heart of the budding yeast cell cycle is an alternation between two selfmaintaining states: the G1 state, in which APC is active,
CDK activity is low, and origins are licensed; and the S/M state, in which APC is shut off, CDK activity is high, and origins are fired and incapable of firing again. The G1 state is self-reinforcing because APC destroys S-phase and Mphase cyclins. The S/M state is self-reinforcing, suggested Nasmyth (1996), because CDKs inactivate the APC by phosphorylating some of its components. Although Nasmyth's proposal contradicted conventional wisdom that B-type cyclins activate the APC, recent experiments in budding yeast confirmed his hypothesis (Amon, 1997; Zachariae et al., 1998; Jaspersen et al., 1999). In Nasmyth's view, the budding yeast division cycle is an alternating sequence of "Start" transitions from G1 to S/M and "Finish" transitions from S/M back to G1. Our goals are to show how these two stable cell cycle states (G1 and S/M) arise from the underlying molecular machinery and to reveal the dynamical nature of the transitions (Start and Finish) between them.

To this end, we summarize experimental results from many sources to construct a consensus picture of the molecular signals controlling cell cycle events in budding yeast. The present picture is built on a simpler model of cell cycle controls in budding yeast (Tyson et al., 1995) and on a mathematical description of Nasmyth's alternating-states hypothesis (Novak et al., 1998). (Those models, along with earlier studies and reviews [Novak and Tyson, 1993, 1995, 1997; Tyson et al., 1996, 1997], should be consulted for an introduction to our theoretical methods, strategies, and tools.)

After casting the mechanism into a set of kinetic equations, we study the dynamical properties of the control system by numerical simulations. Experimental data are used to estimate the crucial kinetic parameters in the model. Then the model is compared with the phenotypes of mutant cells in which various components of the control system are knocked out or overexpressed.

The model, which accounts for most of the distinctive characteristics of the budding yeast cell cycle, is valuable in bringing together a huge amount of hard-won experimental data in a convenient mathematical repository. As experimentalists think about yet unknown details around the "edges" of the consensus picture, the model can be used to explore the properties of hypothetical mechanisms. As new advances are made, the model can be extended to give an ever more comprehensive picture of cell cycle controls in budding yeast.

\section{A CONSENSUS PICTURE OF CELL CYCLE CONTROLS IN BUDDING YEAST}

\section{Cyclin-dependent Kinase Activities}

Major cell cycle events in budding yeast are controlled by a single CDK (Cdc28) in conjunction with two families of cyclins: Cln1-3 and Clb1-6 (Nasmyth, 1993; Mendenhall and Hodge, 1998). Cln1/Cdc28 and Cln2/Cdc28 play major roles in budding and spindle pole body duplication. Cln3/ Cdc28 seems to govern the size at which newborn cells execute Start. Clb5/Cdc28 and Clb6/Cdc28 are essential for timely DNA replication. $\mathrm{Clb3} / \mathrm{Cdc} 28$ and $\mathrm{Clb} 4 / \mathrm{Cdc} 28$ seem to assist in DNA replication and spindle formation. Clb1/ $\mathrm{Cdc} 28$ and $\mathrm{Clb} 2 / \mathrm{Cdc} 28$ are necessary for proper completion of mitosis. 
The roles of these cyclins overlap. All the single mutants are viable and nearly normal, except $\operatorname{cln} 3$ mutants, which execute Start at about twice the size of wild-type cells (Dirick et al., 1995). (Notation, for example, wild-type allele $=C L N 3$, recessive mutant allele $=\operatorname{cn} 3$, dominant mutant allele $=$ $C L N 3^{\mathrm{D}}$, and gene product $=\mathrm{Cln} 3$.) Although the triple-cln mutant, $\ln 1 \operatorname{cln} 2 \operatorname{cln} 3$, is lethal (Richardson et al., 1989), the $\operatorname{cln} 1 \operatorname{cln} 2$ double mutant is large and viable and able to bud. Apparently any one of the Clns can do the essential jobs of the other two, if the cell is large enough. The double mutant clb3 clb4 is normal (Richardson et al., 1992; Schwob and Nasmyth, 1993), so their roles can be played by other Clbs. Because a clb5 clb6 mutant cell carries out DNA synthesis (although with some delay), whereas a cell with all six CLB genes deleted (clb1-6) does not, $\mathrm{Clb1}-4$ can trigger DNA synthesis in the absence of Clb5-6 (Schwob et al., 1994). Only the Clb1-2 pair is special in the sense that at least one of them is necessary for completing mitosis (Surana et al., 1991). Because of these redundancies, it will be sufficient to consider the interaction of Cdc28 with only four classes of cyclins: "Cln2" (representing the combined activities of $C \ln 1$ and $\mathrm{Cln} 2), \mathrm{Cln} 3$, "Clb2" (Clb1 and Clb2 combined), and "Clb5" (Clb5 and Clb6 combined). We do not keep track of Clb3-4 in this model.

\section{Regulation of Cyclin-dependent Kinase Activities}

Cyclin/Cdc28 activities come and go in a characteristic sequence during the budding yeast cell cycle. Regulation is achieved mainly through the synthesis and degradation of cyclin components and of the Clb-dependent kinase inhibitor Sic1. Cln3 is present at low and nearly constant levels throughout the cell cycle; Cln2 and its associated kinase activity are maximal at Start (Wittenberg et al., 1990; Tyers et al., 1993). The pattern of Clb5 is similar to that of Cln2 (Schwob and Nasmyth, 1993), whereas Clb2 and its associated kinase activity peak $\sim 10 \mathrm{~min}$ before anaphase (Surana et al., 1991). Furthermore, Sic1 is present in high concentration in G1 and decreases to low levels after Start (Donovan et al., 1994; Schwob et al., 1994).

In many eukaryotic organisms, Cdk activity is also controlled by inhibitory phosphorylation at a conserved tyrosine in the $\mathrm{N}$ terminus of its kinase subunit. Although budding yeast has this tyrosine residue (Tyr-19 in Cdc28) and the kinase and phosphatase (Swe1 and Mih1) that regulate phosphorylation of this site, tyrosine phosphorylation does not play an important role in regulating Cdk activities during normal vegetative growth (Amon et al., 1992; Sorger and Murray, 1992).

\section{Transcription Factors}

Expression of the CLN2 gene (Koch et al., 1996) is controlled by the transcription factor SBF (Swi4/Swi6) (Nasmyth and Dirick, 1991), which can be activated by all three Cln-associated as well as Clb5-associated kinases (Cross and Tinkelenberg, 1991; Schwob and Nasmyth, 1993) and inactivated by Clb2-associated kinase (Amon et al., 1993). The transcription factor MBF (Mbp1/Swi6) for the CLB5 gene is activated, like SBF, by the Cln- and Clb5-associated kinases (Koch et al., 1993; Schwob and Nasmyth, 1993) but inactivated in G2 by some yet unknown mechanism other than Clb2/Cdc28 kinase (Amon et al., 1993). Transcription of
CLB2 is autocatalytic, because $\mathrm{Clb2} / \mathrm{Cdc} 28$ activates its own transcription factor (Mcm1/SFF) (Amon et al., 1993; Maher et al., 1995). Finally, SIC1 transcription, regulated by Swi5, peaks at anaphase (Knapp et al., 1996). Swi5 is inactivated by Clb2-dependent phosphorylation, which prevents it from entering the nucleus (Nasmyth et al., 1990). It is activated, on the other hand, by a phosphatase, Cdc14, which is in turn activated indirectly by Cdc20 (Visintin et al., 1998; Jaspersen et al., 1999), an ancillary protein for the APC-dependent degradation machinery to be described in the next section.

\section{Proteolysis}

All cyclins are degraded by proteasomes, which destroy proteins that have been tagged by ubiquitin. Ubiquitin tagging is carried out by complex enzymatic machinery that activates ubiquitin molecules, recognizes appropriate proteins to be destroyed, and transfers activated ubiquitin to these doomed proteins (King et al., 1996; Peters, 1998; Zachariae and Nasmyth, 1999). For cyclins, two ubiquitinconjugating protein complexes are known: the APC and the SCF. The APC is composed of a dozen proteins, including Cdc16, -23, and -27, (Zachariae et al., 1996). The SCF is a complex of Skp1, Cdc34, Cdc53, and an F box-containing protein, like Cdc4 or Grr1 (Jackson, 1996; Krek, 1998). The $\mathrm{APC}$ is responsible for destruction of Clb2 (Irniger et al., 1995), Clb5 (partly) (Irniger and Nasmyth, 1997), Cdc20 (Shirayama et al., 1998), and Pds1 (Yamamoto et al., 1996), a protein that promotes sister chromatid cohesion until anaphase. The SCF is responsible for destruction of Cln2 (Deshaies et al., 1995; Willems et al., 1996), Cln3 (Yaglom et al., 1995), and Sic1 (Feldman et al., 1997). Because Clb5 is more stable in $s k p 1$ mutants than in wild-type cells (Bai et al., 1996), Clb5 may be partly degraded by SCF.

Both APC and SCF require ancillary proteins, whose job is to recognize appropriate protein substrates and present them to the ubiquitin-conjugating machinery. For example, Cdc4 presents Sic1, and Grr1 presents Cln2 and Cln3 to the SCF (Barral et al., 1995; Feldman et al., 1997; Li and Johnston, 1997; Skowyra et al., 1997). In like manner, Hct1 (also called Cdh1) presents $\mathrm{Clb2}$, and Cdc20 presents Pds1 and Clb5 to the APC (Schwab et al., 1997; Visintin et al., 1997).

The SCF seems to be active at all times in the cell cycle. Degradation of its target proteins is controlled by the phosphorylation state of the target (Willems et al., 1996). For example, in G1 phase, Sic1 is unphosphorylated and stable, even though the SCF is active. When $C \ln 2$-associated kinase activity rises at Start, Sic1 is phosphorylated, and Sic1P is rapidly presented by Cdc4 to the SCF for ubiquitination and subsequent proteolysis (Verma et al., 1997). Likewise, Cln2 must be phosphorylated before it is recognized by Grr1 (Barral et al., 1995; Li and Johnston, 1997).

APC-dependent proteolysis, on the other hand, is controlled by phosphorylation of the ubiquitination machinery itself, rather than the target proteins. There is evidence in clam oocyte extract (Lahav-Baratz et al., 1995; Sudakin et al., 1995), Xenopus egg extract (Felix et al., 1990; Peters et al., 1996), and mammalian cells (Kotani et al., 1998) that the APC core is activated by phosphorylation and that CDKs may be involved in this activation indirectly via a polo-like kinase (whose homologue in budding yeast is Cdc5) (Descombes and Nigg, 1998; Kotani et al., 1998). But such effects are not 
yet well established in budding yeast, so we do not try to model them in the present paper.

Rather, we focus on the ancillary proteins, which seem to exist in active and inactive forms. For the Hct1-dependent degradation machinery, Amon (1997) showed that, in vivo, cyclin proteolysis can be turned off by ectopic expression of Clb2 (and back on again by expression of Sic1). Recent experiments (Zachariae et al., 1998; Jaspersen et al., 1999) show that, in vitro, CDKs can phosphorylate Hct1, rendering it incapable of interaction with the APC core. Together, these findings confirm Nasmyth's (1996) hypothesis that $\mathrm{CDK}$ activity and $\mathrm{Clb}$ proteolysis are antagonistic events: CDK inactivates APC by phosphorylation, whereas APC destroys CDK activity by degradation of cyclin components. The phosphatase that opposes CDK (and thereby activates Hct1) is Cdc14. Notice that the kinase-phosphatase pair, CDK-Cdc14, regulates not only the activity of Hct1 but also the synthesis (Swi5) and degradation (phosphorylation state) of Sic1 (Visintin et al., 1998; Jaspersen et al., 1999).

The Cdc20-dependent degradation machinery is more complicated still. As cells exit from mitosis, it is responsible for degradation of Pds1, which restrains the dissociation of cohesins by binding to and inhibiting Esp1, a protein essential for sister chromatid separation (Ciosk et al., 1998). Cdc20 is also responsible for loss of an inhibitor of Cdc14 (Novak et al., 1999), leading to activation of Hct1 and Swi5 (Visintin et al., 1997; Lim et al., 1998; Shirayama et al., 1998). The RENT complex, recently identified by Shou et al. (1999) and Visintin et al. (1999), may inhibit Cdc14 by reversible sequestration.

\section{Mitotic Checkpoint}

It has been shown (Hwang et al., 1998) that Cdc20 is a likely target for signals from unaligned chromosomes, unreplicated DNA, and damaged DNA, all of which keep Cdc20 in its inactive form. Unreplicated DNA, in addition to keeping Cdc20 inactive, seems to impinge on the APC-activating pathway as well (Hwang et al., 1998; Kotani et al., 1998). The end result is that, when DNA replication is complete and all chromosomes are in tension on the metaphase plate, APC is phosphorylated, and Cdc20 is activated, leading to degradation of Pds1 (hence, dissolution of cohesions) and to activation of Hct1 (hence, destruction of $\mathrm{Clb} 2$ ).

\section{KINETIC MODEL}

From these facts we construct a consensus picture (Figure 2) of cell cycle controls in budding yeast. Using standard principles of biochemical kinetics, we cast the molecular mechanism into a set of nine, nonlinear, ordinary differential equations governing the temporal changes of cyclins and their regulatory proteins, plus four auxiliary differential equations describing cell growth and CDKinduced events (activation of DNA replication origins, bud emergence, and spindle assembly), plus three algebraic equations determining the activities of SBF, Mcm1, and Swi5 transcription factors (Table 1). About 50 parameters enter into the definitions of these equations, and their values (for wild-type cells) are specified in Table 2. Appendix A, describes how these parameter values were estimated.

The model involves a number of specific kinetic assumptions that are introduced either to simplify the model or to explain specific characteristics of wild-type and mutant cell cycles, as we shall describe. Here we list these assumptions for easy reference.
1) Cell size is coupled to the CDK engine by assuming that the synthesis of each cyclin is proportional to mass, a variable representing overall cell "size." (For simplicity, we assume that mass increases exponentially.) We have in mind that cyclins are synthesized in the cytoplasm, where ribosome number increases throughout the cycle, and accumulate in the nucleus, whose volume does not change much. Thus, the concentrations of cyclins in the nucleus, [Cln2], [Clb2], etc., tend to increase as mass increases. Although many experiments demonstrate that budding yeast division cycles are controlled by cell size (Carter, 1981) through effects on CDK activities (Baroni et al., 1994; Tokiwa et al., 1994; Polymenis and Schmidt, 1997), the molecular mechanism whereby cells measure their nucleocytoplasmic ratio has not yet been elucidated. Our hypothesis, although speculative, is the simplest way to couple growth and division.

2) Transcription of CLB5 is controlled by MBF, but the signal that inactivates MBF is unknown at present, so our picture is incomplete. Because MBF and SBF turn on and off at similar times in the cell cycle, under most conditions (Koch and Nasmyth, 1994; Cho et al., 1998; Spellman et al., 1998), we assume for the time being that [MBF] $=[\mathrm{SBF}]$. When MBF regulation is better understood, this part of the model can be easily improved.

3) The activation and inactivation of transcription factors (SBF Mcm1, and Swi5) are modeled as Goldbeter-Koshland (1981) ultrasensitive switches, as described in Appendix B. We could have represented the sigmoidal behavior of these switches by simpler functions, but the Goldbeter-Koshland function is particularly suitable for the phosphorylation-dephosphorylation reactions typical of cell cycle controls

4) Bck2 cooperates with $\mathrm{Cln} 3$ in activating SBF at Start.

5) At high dosage, the activity of $C \ln 3$-dependent kinase plateaus.

6) We assume first-order kinetics for degradation of $\mathrm{Cln} 2$ and Clb5 by SCF. We are aware that SCF-catalyzed ubiquitination depends on prior phosphorylation of its substrates, most likely by CDKs themselves. Nonetheless, we choose simple first-order kinetics for cyclin degradation in the present model. Later versions can be improved in this regard, if necessary.

7) To describe how CDK activities drive DNA synthesis, bud emergence, and mitotic events, we introduce three "target" variables: ORI, BUD, and SPN. These targets are phosphorylated by CDKs, and the associated physiological events occur when their cumulative level of phosphorylation reaches a threshold (1 in each case).

8) In the present model, $\mathrm{Clb} 2$-dependent kinase stimulates the synthesis of Cdc20 (Prinz et al., 1998) and indirectly activates it by driving [SPN] toward 1 . The function of [SPN] is to provide a time delay between the appearance of $\mathrm{Clb} 2$ and the activation of $\mathrm{Cdc} 20$. To model the effect of nocodazole, we block the activation of Cdc20.

9) Metaphase checkpoint controls are the most primitive part of the model. We assume that Cdc20 is kept inactive until all chromosomes are properly aligned on the mitotic spindle $([\mathrm{SPN}]=1)$. After it is activated, Cdc20 helps activate Hct1 and Swi5, presumably by degrading some inhibitor of Cdc14 (Novak et al., 1999). In a later model, we will track the kinetics of Cdc14 and its sequestration in RENT complexes, but for now we simply allow Cdc20 to activate Hct1 and Swi5 directly.

10) $\mathrm{Cdc} 20$ degrades $\mathrm{Clb} 2$, to some extent.

Intuitively, the diagram in Figure 2 seems appealing, but the hand-waving arguments used to justify it are not entirely convincing. Exactly what experiments can this model account for and what does it leave unexplained? The only way to address this question is to study the mathematical model (Table 1) thoroughly and rigorously, comparing its solution with the physiology of real cells. Where there is a correspondence between the model and reality, we can have some confidence that our understanding of the budding yeast cell cycle is adequate. Where the model fails will point to aspects of the control system that need further study. 
Figure 2. Molecular model of the control of CDK activities during the budding yeast cell cycle. We lump together redundant cyclins $(\mathrm{Cln} 1+$ $\mathrm{Cln} 2=$ "Cln2," $\mathrm{Clb} 1+\mathrm{Clb} 2=$ "Clb2," and Clb5 + Clb6 = "Clb5") and ignore $\mathrm{Clb3}$ and $\mathrm{Clb} 4$. (Notice that we do not draw the kinase subunit, Cdc28, that is associated with each cyclin, because we assume it is in excess.) At the beginning of the cycle, the cell has few cyclin molecules, because the transcription factors (SBF, MBF, and Mcm1) that regulate cyclin synthesis are inactive. $\mathrm{Clb}$-dependent kinases, in addition, are suppressed by a stoichiometric inhibitor (Sic1) and by efficient proteolysis of cyclin subunits. Cln3/ Cdc28, which is present at low and nearly constant activity throughout the cycle, triggers a sequence of events leading ultimately to cell division. The sequence can be read from left to right. When the cell grows to a sufficiently large size, Cln3/Cdc28 and Bck2 activate SBF and MBF (by phosphorylation, so we assume), causing $\mathrm{Cln} 2$ and $\mathrm{Clb} 5$ to begin to accumulate. At first, $\mathrm{Clb5}$ accumulates in inactive trimers, Clb5/ Cdc28/Sic1, but $\mathrm{Cln} 2 / \mathrm{Cdc} 28$ is not so inhibited. Rising Cln2/Cdc28 activity plays three important roles.

First, it initiates bud formation. Second, it phosphorylates Sic1, priming the inhibitor for ubiquitination by SCF and ultimate degradation by the proteasome. Third, it inactivates Hct1, which, in conjunction with APC, was responsible for Clb2 degradation in G1 phase. When Sic1 is destroyed, $\mathrm{Clb5} / \mathrm{Cdc} 28$ activity rises abruptly and drives the cell into $\mathrm{S}$ phase. These are the major physiological events associated with the Start transition. With Sic1 gone and Hct1 inactivated, Clb2-dependent kinase can begin to rise, with some lag, because Clb2/Cdc28 activates its own transcription factor, Mcm1. In addition, Clb2/Cdc28 inactivates SBF, so Cln2-dependent kinase activity begins to fall as Cln2 synthesis shuts off. At about the same time, MBF is inactivated, and the $\mathrm{Clb5}$ level starts to fall. Rising $\mathrm{Clb2} / \mathrm{Cdc} 28$ activity induces progress through mitosis. The metaphaseanaphase transition is regulated by a pair of proteins, Cdc20 and Hct1, that target substrates to the APC for ubiquitination. At metaphase, they are inactive, but when DNA is fully replicated and all chromosomes are aligned on the metaphase plate, Cdc20 is activated. Indirectly Cdc20 promotes 1) dissociation of sister chromatids (anaphase A), 2) activation of Hct1, which conducts Clb2 to the APC, thereby initiating anaphase B and cell separation, and 3) activation of Swi5, the transcription factor for Sic1. With all CDK activity gone (except for a little associated with Cln3), Sic1 can make a comeback, and the cell returns to G1.

\section{RESULTS}

\section{Wild-Type Cell Cycle}

Figure 3 presents a numerical solution of the kinetic equations (Table 1), using a basal set of rate constants (Table 2), suitable for wild-type division cycles (see Appendix A for a justification of the parameter values). In this case, the massdoubling time $\left(\mathrm{T}_{\mathrm{d}}\right)$ of the culture is $120 \mathrm{~min}$ (specific growth rate $=\mu=0.693 / \mathrm{T}_{\mathrm{d}}=0.005776 \mathrm{~min}^{-1}$ ). Because division is asymmetrical, we must distinguish between mother and daughter cells. The smaller daughter cells (Table 3, line 1) have a longer cycle time (146 min from birth to division), because they require more time to grow to the critical size when SBF turns on. (In our model, SBF is turned on abruptly by $\mathrm{Cln} 3$ when mass $\approx 1.1$; see Appendix B.) Mother cells have a cycle time of $100 \mathrm{~min}$, because they turn on SBF more quickly after division. On the other hand, the budded phases of mother and daughter cells are quite similar ( $\sim 60 \mathrm{~min})$.
Start and Finish. Two major transitions characterize wild-type cell cycles (Figure 3). At Start, a series of events is initiated in rapid succession: SBF turns on, $\mathrm{Cln} 2$ and $\mathrm{Clb} 5$ levels rise, Sic1 disappears, Hct1 turns off, and DNA synthesis and bud emergence commence. Shortly thereafter, Clb2 level rises and a spindle starts to form. At Finish, Cdc20 and Hct1 turn on, Clb2 is destroyed, and Sic1 makes a comeback. In simulations of various mutant strains, we will see how these chains of events can be dissociated.

The first event of Start is abrupt activation of SBF, when cells grow to a critical size, as demonstrated experimentally (Dirick et al., 1995; Stuart and Wittenberg, 1995). In our simulations, SBF turns on abruptly because it is modeled as an ultrasensitive switch (Goldbeter and Koshland, 1981), driven by the accumulation of $\mathrm{Cln} 3$ and Bck 2 in the nucleus as the cell grows to the critical size. When the combined activities of $\mathrm{C} \ln 3$ and $\mathrm{Bck} 2, k_{\mathrm{a}, \mathrm{sbf}} \times \varepsilon_{\mathrm{sbf}, \mathrm{n} 3} \times\left([\mathrm{Cln} 3]^{*}+\right.$ [Bck2]), exceed the activity of the opposing phosphatase, $k_{\mathrm{i}, \mathrm{sbf}}$, then SBF turns on (see Appendix B). With our param- 
Table 1. Mathematical model of the budding yeast cell cycle

Equations governing cyclin-dependent kinases

$\frac{\mathrm{d}}{\mathrm{dt}}[\mathrm{Cln} 2]=\left(k_{\mathrm{s}, \mathrm{n} 2}^{\prime}+k_{\mathrm{s}, \mathrm{n} 2}^{\prime \prime}[\mathrm{SBF}]\right) \cdot \operatorname{mass}-k_{\mathrm{d}, \mathrm{n} 2}[\mathrm{Cln} 2]$

$\frac{\mathrm{d}}{\mathrm{dt}}[\mathrm{Clb} 2]_{\mathrm{T}}=\left(k_{\mathrm{s}, \mathrm{b} 2}^{\prime}+k_{\mathrm{s}, \mathrm{b} 2}^{\prime \prime}[\mathrm{Mcm} 1]\right) \cdot \operatorname{mass}-V_{d, b 2}[\mathrm{Clb} 2]_{\mathrm{T}}, V_{d, b 2}=k_{\mathrm{d}, \mathrm{b} 2}^{\prime}\left([\mathrm{Hct} 1]_{\mathrm{T}}-[\mathrm{Hct} 1]\right)+k_{\mathrm{d}, \mathrm{b} 2}^{\prime \prime}[\mathrm{Hct} 1]+k_{\mathrm{d}, \mathrm{b} 2}^{\prime \prime}[\mathrm{Cdc} 20]$

$\frac{\mathrm{d}}{\mathrm{dt}}[\mathrm{Clb} 5]_{\mathrm{T}}=\left(k_{\mathrm{s}, \mathrm{b} 5}^{\prime}+k_{\mathrm{s}, \mathrm{b} 5}^{\prime \prime}[\mathrm{MBF}]\right) \cdot \operatorname{mass}-V_{d, b 5} \cdot[\mathrm{Clb} 5]_{\mathrm{T}}, V_{d, b 5}=k_{\mathrm{d}, \mathrm{b5}}^{\prime}+k_{\mathrm{d}, \mathrm{b} 5}^{\prime \prime}[\mathrm{Cdc} 20]$

$[\mathrm{Bck} 2]=[\mathrm{Bck} 2]^{0} \cdot$ mass, $\quad[\mathrm{Cln} 3]^{*}=[\mathrm{Cln} 3]_{\max } \frac{D_{n 3} \cdot \operatorname{mass}}{J_{\mathrm{n} 3}+D_{n 3} \cdot \operatorname{mass}}$

$[\mathrm{Clb} 2]_{\mathrm{T}}=[\mathrm{Clb} 2]+[\mathrm{Clb} 2 / \mathrm{Sic} 1], \quad[\mathrm{Clb} 5]_{\mathrm{T}}=[\mathrm{Clb} 5]+[\mathrm{Clb} 5 / \mathrm{Sic} 1]$

$[\mathrm{Sic} 1]_{\mathrm{T}}=[\mathrm{Sic} 1]+[\mathrm{Clb} 2 / \mathrm{Sic} 1]+[\mathrm{Clb} 5 / \mathrm{Sic} 1]$

Equations governing the inhibitor of $\mathrm{Clb}$-dependent kinases

$\frac{\mathrm{d}}{\mathrm{dt}}[\mathrm{Sic} 1]_{\mathrm{T}}=k_{\mathrm{s}, \mathrm{c} 1}^{\prime}+k_{\mathrm{s}, \mathrm{c} 1}^{\prime \prime}[\mathrm{Swi} 5]-\left(k_{\mathrm{d} 1, \mathrm{c} 1}+\frac{V_{\mathrm{d} 2, c 1}}{J_{\mathrm{d} 2, \mathrm{c} 1}+[\mathrm{Sic} 1]_{\mathrm{T}}}\right) \cdot[\mathrm{Sic} 1]_{\mathrm{T}}$

$\frac{\mathrm{d}}{\mathrm{dt}}[\mathrm{Clb} 2 / \mathrm{Sic} 1]=k_{\mathrm{as}, \mathrm{b} 2}[\mathrm{Clb} 2] \cdot[\mathrm{Sic} 1]-\left(k_{\mathrm{di}, \mathrm{b} 2}+V_{d, b 2}+k_{\mathrm{d} 1, \mathrm{c} 1}+\frac{V_{d 2, c 1}}{J_{\mathrm{d} 2, c 1}+[\mathrm{Sic} 1]_{\mathrm{T}}}\right) \cdot[\mathrm{Clb} 2 / \mathrm{Sic} 1]$

$\frac{\mathrm{d}}{\mathrm{dt}}[\mathrm{Clb} 5 / \mathrm{Sic} 1]=k_{\mathrm{as}, \mathrm{b} 5}[\mathrm{Clb} 5] \cdot[\mathrm{Sic} 1]-\left(k_{\mathrm{di}, \mathrm{b} 5}+V_{d, b 5}+k_{\mathrm{d} 1, \mathrm{c} 1}+\frac{V_{d 2, c 1}}{J_{\mathrm{d} 2, c 1}+[\mathrm{Sic} 1]_{\mathrm{T}}}\right) \cdot[\mathrm{Clb} 5 / \mathrm{Sic} 1]$

$V_{\mathrm{d} 2, \mathrm{c} 1}=k_{\mathrm{d} 2, \mathrm{c} 1}\left(\varepsilon_{\mathrm{c} 1, \mathrm{nn} 3}[\mathrm{Cln} 3]^{*}+\varepsilon_{\mathrm{c} 1, \mathrm{k} 2}[\mathrm{Bck} 2]+[\mathrm{Cln} 2]+\varepsilon_{\mathrm{c} 1, \mathrm{~b} 5}[\mathrm{Clb} 5]+\varepsilon_{\mathrm{c} 1, \mathrm{~b} 2}[\mathrm{Clb} 2]\right)$

Equations governing the $\mathrm{Clb}$ degradation machinery

$\frac{\mathrm{d}}{\mathrm{dt}}[\mathrm{Cdc} 20]_{\mathrm{T}}=\left(k_{\mathrm{s}, 20}^{\prime}+k_{\mathrm{s}, 20}^{\prime \prime}[\mathrm{Clb} 2]\right)-k_{\mathrm{d}, 20}[\mathrm{Cdc} 20]_{\mathrm{T}}$

$\frac{\mathrm{d}}{\mathrm{dt}}[\mathrm{Cdc} 20]=k_{\mathrm{a}, 20}\left([\mathrm{Cdc} 20]_{\mathrm{T}}-[\mathrm{Cdc} 20]\right)-\left(V_{i, 20}+k_{\mathrm{d}, 20}\right) \cdot[\mathrm{Cdc} 20]$

$V_{\mathrm{i}, 20}= \begin{cases}k_{i, 20}^{\prime}, & \text { for END_M }+12 \min <\mathrm{t}<\text { START_S } \\ k_{i, 20}^{\prime \prime}, & \text { for START_S }<\mathrm{t}<\text { END_M }\end{cases}$

$\frac{\mathrm{d}}{\mathrm{dt}}[$ Hct 1$]=\frac{\left(k_{\mathrm{a}, \mathrm{t} 1}^{\prime}+k_{\mathrm{a}, \mathrm{t}}^{\prime \prime}[\text { Cdc20] }]\right) \cdot\left([\text { Hct } 1]_{\mathrm{T}}-[\text { Hct } 1]\right)}{J_{\mathrm{a}, \mathrm{t} 1}+[\text { Hct } 1]_{\mathrm{T}}-[\text { Hct } 1]}-\frac{V_{i, t 1}[\text { Hct } 1]}{J_{\mathrm{i}, \mathrm{t} 1}+[\text { Hct } 1]}$

$V_{i, t 1}=k_{i, t 1}^{\prime}+k_{i, t 1}^{\prime \prime}\left([\mathrm{Cln} 3]^{*}+\varepsilon_{\mathrm{i}, t 1, \mathrm{n} 2}[\mathrm{Cln} 2]+\varepsilon_{\mathrm{i}, \mathrm{t} 1, \mathrm{~b}}[\mathrm{Clb} 5]+\varepsilon_{\mathrm{i}, \mathrm{t} 1 \mathrm{~b} 2}[\mathrm{Clb} 2]\right)$

Equations for growth, DNA synthesis, budding and spindle formation

$\frac{\mathrm{d}}{\mathrm{dt}}$ mass $=\mu \cdot$ mass, $\frac{\mathrm{d}}{\mathrm{dt}}[\mathrm{ORI}]=k_{\mathrm{s}, \text { ori }}\left([\mathrm{Clb} 5]+\varepsilon_{\text {ori, }, 2}[\mathrm{Clb} 2]\right)-k_{\mathrm{d}, \text { oril }}[\mathrm{ORI}]$

$\frac{\mathrm{d}}{\mathrm{dt}}[\mathrm{BUD}]=k_{\mathrm{s}, \mathrm{bud}}\left([\mathrm{Cln} 2]+[\mathrm{Cln} 3]^{*}+\varepsilon_{\mathrm{bud}, \mathrm{b} 5}[\mathrm{Clb} 5]\right)-k_{\mathrm{d}, \mathrm{bud}}[\mathrm{BUD}], \frac{\mathrm{d}}{\mathrm{dt}}[\mathrm{SPN}]=k_{\mathrm{s}, \mathrm{spn}} \frac{[\mathrm{Clb} 2]}{J_{\mathrm{spn}}+[\mathrm{Clb} 2]}-k_{\mathrm{d}, \mathrm{spn}}[\mathrm{SPN}]$

Equations governing transcription factors

$[\mathrm{SBF}]=[\mathrm{MBF}]=\mathrm{G}\left(\mathrm{V}_{\mathrm{a}, \mathrm{sbf}}, k_{\mathrm{i}, \mathrm{sbf}}^{\prime}+k_{\mathrm{i}, \mathrm{sbf}}^{\prime \prime}[\mathrm{Clb} 2], J_{\mathrm{a}, \mathrm{sbf}}, J_{\mathrm{i}, \mathrm{sbf}}\right), V_{\mathrm{a}, \mathrm{sbf}}=k_{\mathrm{a}, \mathrm{sbf}}\left([\mathrm{Cln} 2]+\varepsilon_{\mathrm{sbf}, \mathrm{n} 3}\left([\mathrm{Cln} 3]^{*}+[\mathrm{Bck} 2]\right)+\varepsilon_{\mathrm{sbf}, \mathrm{b} 5}[\mathrm{Clb} 5]\right)$,

$[\mathrm{Mcm} 1]=\mathrm{G}\left(k_{\mathrm{a}, \mathrm{mcm}}[\mathrm{Clb} 2], k_{\mathrm{i}, \mathrm{mcm}}, J_{\mathrm{a}, \mathrm{mcm}}, J_{\mathrm{i}, \mathrm{mcm}}\right),[\mathrm{Swi} 5]=\mathrm{G}\left(k_{\mathrm{a}, \mathrm{swi}}[\mathrm{Cdc} 20], k_{\mathrm{i}, \mathrm{swi}}^{\prime}+k_{\mathrm{i}, \text { swi }}^{\prime \prime}[\mathrm{Clb} 2], J_{\mathrm{a}, \mathrm{swi}}, J_{\mathrm{i}, \mathrm{swi}}\right)$

Symbols, $V=$ rate functions, $k=$ rate constant, $J=$ Michaelis constant. Subscripts, $\mathrm{s}=$ synthesis, $\mathrm{d}=$ degradation, $\mathrm{a}=$ activation, $\mathrm{i}=$ inactivation, as = association, $\mathrm{di}=$ dissociation, $\mathrm{T}=$ total.

${ }^{a} k_{\mathrm{d}, \mathrm{b} 5}^{\prime}$ refers to SCF-mediated degradation of $\mathrm{Clb5}$, and $k_{\mathrm{d}, \mathrm{b} 5}^{\prime}$ refers to its APC-mediated degradation.

${ }^{b} \mathrm{~d} 1, \mathrm{c} 1$ refers to the degradation of unphosphorylated Sic1. d2,c1 refers to the rate of phosphorylation of Sic1 by cyclin-dependent kinases, assuming that phosphorylated Sic1 is rapidly proteolyzed, releasing active Cdc $28 / \mathrm{Clb}$ dimers.

c START_S is the time when [ORI] $=1$, and END_M when $[S P N]=1$. For START_S $<\mathbf{t}<$ END_M, there is a strong inhibitory signal on Cdc20 $\left(V_{\mathrm{i}, 20}=10\right)$. Once the cell reaches metaphase $(\mathrm{t}=$ END_M $), V_{\mathrm{i}, 20}$ drops linearly from 10 to 0.1 over 12 min. Thereafter, $V_{\mathrm{i}, 20}=0.1$ until the start of the next $S$ phase.

${ }^{d}$ Cell division occurs, we assume, when [Clb2] drops below a threshold (0.3). At this time, we divide mass between mother and daughter cells as follows: (mass of daughter cell at birth) $=f \times$ (mass at cell separation), (mass of mother cell at birth) $=(1-f) \times($ mass at cell separation), with $f=\mathrm{e}^{-\mu \mathrm{D}}$, where $D=(1.026 / \mu)-32$ is the observed daughter cell cycle time (Lord and Wheals, 1980). (See text for a discussion of the rule for asymmetric division.) At division, we also reset BUD and SPN to zero; however, we reset ORI to zero (for licensing factor to reappear after mitosis) only when [Clb2] + [Clb5] drop below a different threshold (0.2).

${ }^{e} \mathrm{G}\left(V_{\mathrm{a}}, V_{\mathrm{i}}, J_{\mathrm{a}}, J_{\mathrm{i}}\right)$ is the Goldbeter-Koshland function described in Appendix B.

eter values, $\mathrm{Cln} 3$ and Bck2 contribute about equally to the activation of SBF.

Finish (exit from mitosis) is triggered by activation of Cdc20. After cells pass Start and begin to synthesize Clb2,
Cdc20 accumulates at an increasing rate. But it remains inactive because of inhibitory signals from unreplicated DNA and unaligned chromosomes. When those events are completed and the inhibitory signals disappear, Cdc20 is 
Table 2. Kinetic constants for the budding yeast model

\begin{tabular}{|c|c|c|c|}
\hline \multicolumn{4}{|l|}{ Rate constants $\left(\mathrm{min}^{-1}\right)$} \\
\hline$k_{\mathrm{s}, \mathrm{n} 2}^{\prime}=0$ & $k_{\mathrm{s}, \mathrm{n} 2}^{\prime \prime}=0.05$ & $k_{\mathrm{d}, \mathrm{n} 2}=0.1$ & \\
\hline $\begin{array}{l}k_{\mathrm{s}, \mathrm{b} 2}^{\prime}=0.002 \\
k_{\mathrm{d}, \mathrm{b} 2}^{\prime}=0.01\end{array}$ & $\begin{array}{l}k_{\mathrm{s}, \mathrm{b} 2}=0.05 \\
k_{\mathrm{d}, \mathrm{b} 2}^{\prime \prime}=2\end{array}$ & $k_{\mathrm{d}, \mathrm{b} 2}^{\prime \prime \prime}=0.05$ & \\
\hline$k_{\mathrm{s}, \mathrm{b} 5}^{\prime}=0.006$ & $k_{\mathrm{s}, \mathrm{b} 5}^{\prime \prime}=0.02$ & $k_{\mathrm{d}, \mathrm{b} 5}^{\prime}=0.1$ & $k_{\mathrm{d}, \mathrm{b} 5}^{\prime \prime}=0.25$ \\
\hline$k_{\mathrm{s}, \mathrm{c} 1}^{\prime}=0.02$ & $k_{\mathrm{s}, \mathrm{c} 1}^{\prime \prime}=0.1$ & $k_{\mathrm{d} 1, \mathrm{c} 1}=0.01$ & $k_{\mathrm{d} 2, \mathrm{c} 1}=0.3$ \\
\hline$k_{\mathrm{as}, \mathrm{b} 2}^{\mathrm{s}, \mathrm{c1}}=k_{\mathrm{as}, \mathrm{b} 5}=50$ & $k_{\mathrm{di}, \mathrm{b} 2}=k_{\mathrm{di}, \mathrm{b} 5}=0.05$ & & \\
\hline$k_{\mathrm{s}, 20}^{\prime}=0.005$ & $k_{s, 20}^{\prime \prime \prime}=0.06$ & $k_{\mathrm{d}, 20}=0.08$ & \\
\hline $\begin{array}{l}k_{\mathrm{a}, 20}=1 \\
k_{\mathrm{a}, \mathrm{t} 1}^{\prime}=0.04\end{array}$ & $\begin{array}{l}k_{\mathrm{i}, 20}^{\prime}=0.1 \\
k_{\mathrm{a}+1}^{\prime \prime}=2\end{array}$ & $\begin{array}{l}k_{i, 20}^{\prime \prime}=10 \\
k_{i, 11}^{\prime}=0\end{array}$ & $k^{\prime \prime}=064$ \\
\hline$k_{\mathrm{s}, \text { ori }}=2$ & $k_{\mathrm{s}, \mathrm{bud}}^{\mathrm{a} t 1}=0.3$ & $k_{\mathrm{s}, \mathrm{spn}}=0.08$ & $h_{i, t 1}-0.04$ \\
\hline $\begin{array}{l}k_{\mathrm{d}, \text { ori }}=k_{\mathrm{d}, \mathrm{bud}}=k_{\mathrm{d}, \mathrm{spn}}=0.06 \\
k_{\mathrm{i} \text { sbf }}^{\prime}=0.5\end{array}$ & $k_{\mathrm{i}_{\mathrm{sbf}}}^{\prime \prime}=6$ & $\begin{array}{l}k_{\mathrm{a}, \mathrm{sbf}}=k_{\mathrm{a}, \mathrm{mcm}}=k_{\mathrm{a}, \mathrm{swi}}=1 \\
k_{\mathrm{s}}^{\prime}=0.3\end{array}$ & $k_{\mathrm{i} w \mathrm{i}}^{\prime \prime}=0.2$ \\
\hline$k_{\mathrm{i}, \mathrm{mcm}}^{1, \mathrm{sDr}}=0.15$ & $\mu \stackrel{1, \text { sft }}{=} 0.005776$ & & $n_{\mathrm{i}, \mathrm{swi}}-0.2$ \\
\hline \multicolumn{4}{|c|}{ Characteristic concentrations (dimensionless) } \\
\hline $\begin{array}{l}{[\mathrm{Cln} 3]_{\max }=0.02} \\
J_{\mathrm{spn}}=0.2\end{array}$ & $\begin{array}{l}{[\mathrm{Bck} 2]^{0}=0.0027} \\
J_{\mathrm{d} 2 \mathrm{c} 1}=0.05\end{array}$ & {$[\text { Hct } 1]_{\mathrm{T}}=1$} & \\
\hline$J_{\mathrm{a}, \mathrm{sbf}}=J_{\mathrm{i}, \mathrm{sbf}}=0.01$ & $J_{\mathrm{a}, \mathrm{mcm}}=J_{\mathrm{i}, \mathrm{mcm}}=1$ & $J_{\mathrm{a}, \mathrm{swi}}=J_{\mathrm{i}, \mathrm{swi}}=0.1$ & $J_{\mathrm{a}, \mathrm{t} 1}=J_{\mathrm{i}, \mathrm{t} 1}=0.05$ \\
\hline \multicolumn{4}{|l|}{ Kinase efficiencies (dimensionless) } \\
\hline$\varepsilon_{\mathrm{c} 1, \mathrm{n} 3}=20$ & $\varepsilon_{\mathrm{c} 1, \mathrm{k} 2}=2$ & $\varepsilon_{\mathrm{c} 1, \mathrm{~b} 2}=0.067$ & $\varepsilon_{\mathrm{c} 1, \mathrm{~b} 5}=1$ \\
\hline$\varepsilon_{\mathrm{i}, \mathrm{t} 1, \mathrm{n} 2}=1$ & $\varepsilon_{\mathrm{i}, \mathrm{t} 1, \mathrm{~b} 2}=1$ & $\varepsilon_{\mathrm{i}, \mathrm{t} 1, \mathrm{~b} 5}=0.5$ & \\
\hline$\varepsilon_{\mathrm{ori}, \mathrm{b} 2}=0.4$ & $\varepsilon_{\text {bud,b5 }}=1$ & $\varepsilon_{\mathrm{sbf}, \mathrm{n} 3}=75$ & $\varepsilon_{\mathrm{sbf,b5}}=0.5$ \\
\hline \multicolumn{4}{|l|}{ Other parameters (dimensionless) } \\
\hline$f=0.433$ & $J_{\mathrm{n} 3}=6$ & $D_{\mathrm{n} 3}=1$ & \\
\hline
\end{tabular}

activated. Active Cdc20 turns on Hct1 by overwhelming the inhibition exerted on Hct1 by Clb2 (presumably by degrading some inhibitor of Cdc14). When Hct1 turns on, Clb2 is degraded, and the control system switches to the G1 state, in which the enemies of Clbs (Hct1 and Sic1) are active.

Response to $\boldsymbol{\alpha}$-Factor. When an asynchronous population of budding yeast cells is exposed to $\alpha$-factor (mating pheromone), pre-Start cells are blocked in G1, but post-Start cells finish DNA replication, divide, and stop in the next G1 phase. $\alpha$-factor initiates a signal transduction pathway that ultimately eliminates all Cln-dependent kinase activities (Chang and Herskowitz, 1990; Peter and Herskowitz, 1994; Wittenberg and Reed, 1996). To simulate $\alpha$-factor treatment, we set the catalytic efficiencies of $C \ln 2$ - and $C \ln 3$-dependent kinases to zero, $10 \mathrm{~min}$ after the time of $\alpha$-factor addition (i.e., assuming a 10-min delay for signal transduction). We found a point of no return shortly before the onset of $S$ phase.

Dependence of Cell Cycle Time on Growth Rate and Birth Size. Figure 1 shows how certain characteristics of wild-type cell cycles depend on mass-doubling time, as reported by Lord and Wheals (1980) and Hartwell and Unger (1977). As $T_{d}$ increases (specific growth rate, $\mu$, decreases), cell division becomes increasingly asymmetrical, daughter size at birth decreases, and the duration of its unbudded phase increases. The unbudded phase of mother cells also increases slightly with $\mathrm{T}_{\mathrm{d}}$.

To fit the model to these data, we must adopt a rule for partitioning cell size to mother and daughter at cell separation. The simplest rule ("Rule 1 ") would be to give to the daughter cell all growth from bud emergence to cell division and let mother retain the mass it had when the bud emerged. However, in this case, the mother would be able to bud soon after its birth; hence it should not have an appreciable unbudded period, which is in contradiction to the observations of Lord and Wheals (1980) and Hartwell and Unger (1977). For the mother cell to have an unbudded period, its birth size must be smaller than the critical size for bud emergence. Furthermore, the calculated daughter cycle times at various growth rates are longer than the observed values. Both results reflect that Rule 1 is inadequate, it gives too much mass to mothers and too little to daughters.

Therefore, we adopt a different rule (Rule 2). Let $f=$ fraction of mass given to the daughter at cell division $(0<$ $f \leq 1 / 2$ ), and choose $f$ to give the observed daughter cycle time (D) at any particular growth rate $\left(\mu=0.693 / \mathrm{T}_{\mathrm{d}}\right)$. From our assumption that cells grow exponentially, (mother size at division $)=($ daughter size at birth $) \times \mathrm{e}^{\mu \mathrm{D}}$, so $f=($ daughter size at birth $) /($ mother size at division $)=\mathrm{e}^{-\mu \mathrm{D}}$. By using the empirical formula for daughter cycle time, $\mathrm{D}=1.48 \mathrm{~T}_{\mathrm{d}}-32$ (Lord and Wheals, 1980, their Table 2) to calculate $\mathrm{f}$, we ensure that the model fits the data for $\mathrm{D}$ as a function of $\mathrm{T}_{\mathrm{d}}$ (Figure 1, top line).

Furthermore, $($ mother size at division $)=($ mother size at birth) $\times \mathrm{e}^{\mu \mathrm{P}}$, where $\mathrm{P}=$ mother cycle time, and (mother size at division $)=($ mother size at birth $)+$ (daughter size at birth). Therefore, $1=\mathrm{e}^{-\mu \mathrm{P}}+\mathrm{e}^{-\mu \mathrm{D}}$. This relation was originally derived by Hartwell and Unger (1977) in a more complicated manner and shown by them to be consistent with the data. Consequently, by choosing $f$ to fit $\mathrm{D}$ as a function of $T_{d}$, we also ensure a good fit to $P$ as a function of $T_{d}$ (Figure 1, middle line).

The dependence of budded period on growth rate (Figure 1 , bottom line) is unconstrained, so its fit to the data is a valid test of the model. Progression through the budded part of the cycle is slightly dependent on growth rate but not nearly so much in the model as in experiments. 


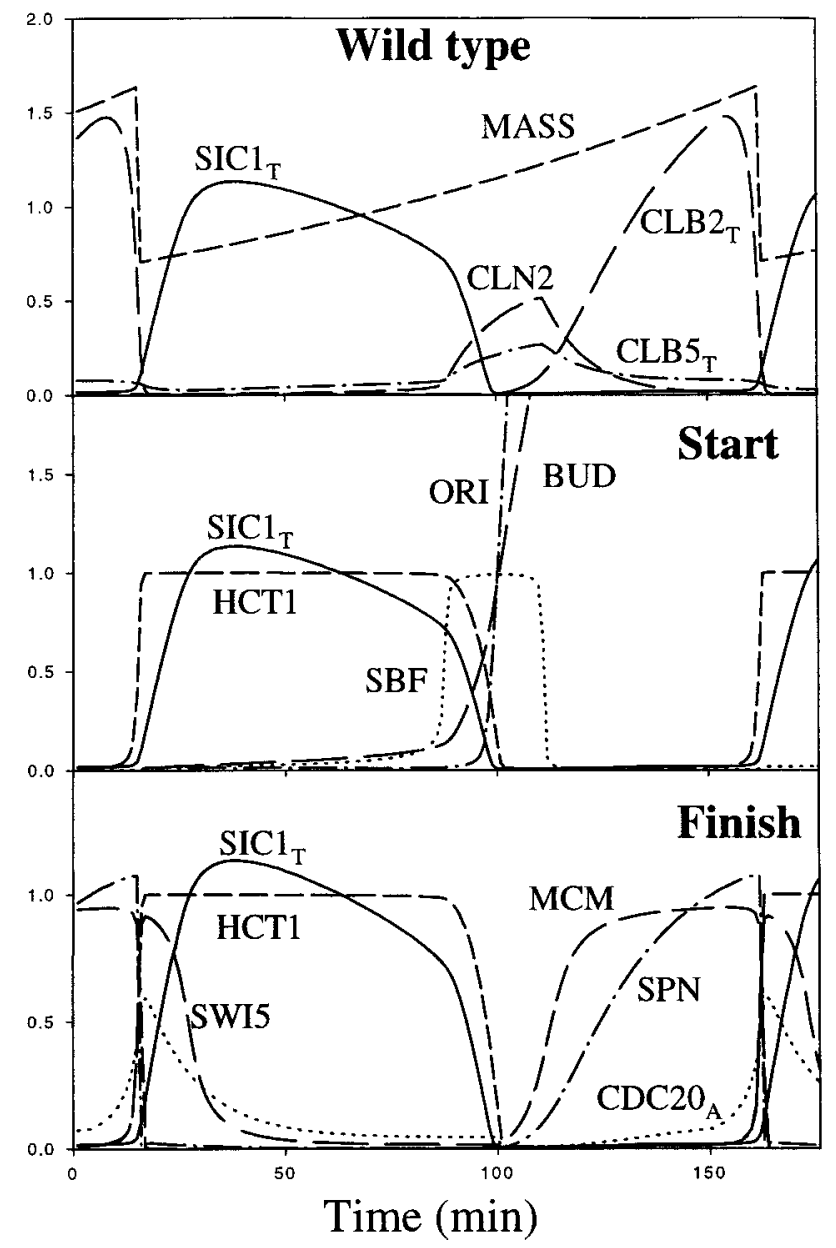

Figure 3. Wild-type cell cycle in daughter cells. Computed from equations and parameter values in Tables 1 and 2.

Under Rule 2, simulations show that mother cells become slightly larger each cycle for the first few cycles (Table 3, line 1 ) but not as much as the observed 25\% increase (Hartwell and Unger, 1977; Johnston et al., 1979); furthermore, mother cells soon reach a steady size. This discrepancy is tied inevitably (in our model) to the prominent unbudded phase of mother cells (Figure 1). Under Rule 2, mother cell birth size is less than the critical mass for SBF activation. Hence, mother cells have an extended unbudded phase, as they grow to this critical mass, and mother cell cycles, like daughter cell cycles, are size regulated. Consequently, mother size at division does not increase steadily with each generation. Under Rule 1, size control is absent from mother cells, and they do grow larger each generation, as observed, but Rule 1 does not fit the observations in Figure 1. We do not know how to resolve this problem.

Similar to the observation of Lord and Wheals (1980), Johnston et al. (1977) reported that the smaller a cell is at birth the longer its unbudded interval is. These data support the proposal that smaller cells need more time to grow to a critical size for bud initiation. Our simulations (Figure 4) agree closely with these observations.

\section{Analysis of Mutants}

Dependence of Cell Size on CLN3 Gene Dosage. That Cln3 plays a major role in size control of budding yeast is suggested by the strong dependence of mean cell size on CLN3 gene dosage (Cross, 1988; Nash et al., 1988; Dirick et al., 1995; Yaglom et al., 1995). Figure 5 presents the model's simulation of this effect. The fact that cells approach a minimal size as CLN3 dosage increases suggests that the activity of Cln3-dependent kinase plateaus at high concentration (assumption 5). The parameter $J_{\mathrm{n} 3}$ determines how fast $[\mathrm{Cln} 3]^{*}$, the kinase activity of $\mathrm{Cln} 3$, saturates with increasing CLN3 dosage, $D_{\mathrm{n} 3}$.

Role of the Positive Feedback Loop. Experimental evidence clearly shows that SBF can be activated by Cln1-2 and Clb5-6 as well as Cln3 (Cross and Tinkelenberg, 1991; Schwob and Nasmyth, 1993), hence the appearance of all three CDK activities in $V_{\mathrm{a}, \mathrm{sbf}}$ (Table 1). In wild-type cells Clb5 can play no role in SBF activation at Start, because any Clb5 present in G1 phase will be tied up in inactive trimers, Sic1/Clb5/Cdc28. However, some active Cln2-dependent kinase is likely present in G1, and it could cooperate with $\mathrm{Cln} 3$ and Bck2 in activating SBF. This positive feedback loop (SBF turns on $\mathrm{Cln} 2$ synthesis, and $\mathrm{Cln} 2 / \mathrm{Cdc} 28$ activates $\mathrm{SBF}$ ) could potentially play a major role in the activation of SBF at Start.

Dirick et al. (1995) and Stuart and Wittenberg (1995) addressed the role of positive feedback by comparing cell size at SBF activation in two mutant strains, $\operatorname{cln} 1 \operatorname{cln} 2$ and $\operatorname{cln} 3$. Each strain was made artificially small at birth by ectopic expression of a wild-type CLN gene carried on a plasmid. Dirick et al. (1995) used CLN2 under the control of a methionine-repressible promoter. In the presence of methionine (plasmid-borne CLN2 not expressed), both strains are larger than normal, and SBF is activated soon after cell division. Cell size in this case is not indicative of the minimum size necessary to activate SBF. To assay the minimum size, cells were grown in the absence of methionine (plasmid-borne CLN2 expressed), so that they grow and divide, like wild type, at a much smaller size. The smallest newborn cells (volume $\sim 10 \mathrm{fl}$ ) were selected by centrifugal elutriation and resuspended in medium containing methionine. In this case, the cells needed to grow awhile before SBF was activated. Cells of the $\ln 1 c \ln 2$ MET-CLN2 strain activated SBF at $19 \mathrm{fl}$, exactly the same size as control cells (CLN1 CLN2 CLN3 MET-CLN2). On the other hand, cells lacking $\mathrm{Cln} 3$ (the $c \ln 3$ MET-CLN2 strain) activated SBF at $\sim 45 \mathrm{fl}$ (Dirick et al., 1995, their Figure 2A).

These remarkable results indicate that 1) positive feedback does not play a determinative role in the activation of SBF at Start (because cell size at SBF activation is unchanged when the positive feedback loop is broken); and 2) there must be some component (other than Cln1-3 and Clb5,6) that turns on SBF in the absence of $\mathrm{Cln} 3$, albeit at a larger size. (Clb5,6 are excluded because deletion mutants have size similar to that of wild-type cells, not twice as big.)

To capture these features with our model, we assume that $\mathrm{Cln} 3$ is much more efficient than Cln2 in activating SBF $\left(\varepsilon_{\mathrm{sbf}, \mathrm{n} 3} \gg 1\right)$, and that $\mathrm{Cln} 3$ is assisted by Bck2 (reasons to be described later). Because the $\ln 3$ mutant is about twice the size of wild type, we choose parameters so that Bck2 and 
Table 3. Properties of wild-type cells and $c \ln$ mutants

\begin{tabular}{|c|c|c|c|c|c|c|c|c|c|}
\hline & & $\begin{array}{l}\text { Mass at } \\
\text { birth }\end{array}$ & $\begin{array}{l}\text { Mass at } \\
\text { SBF } 50 \%\end{array}$ & $\begin{array}{l}\text { Mass at } \\
\text { DNA repl. }\end{array}$ & $\begin{array}{l}\text { Mass at } \\
\text { bud ini. }\end{array}$ & $\begin{array}{l}\text { Mass at } \\
\text { division }\end{array}$ & $\begin{array}{c}\mathrm{T}_{\mathrm{G} 1} \\
(\mathrm{~min})\end{array}$ & $\begin{array}{l}\text { Changed } \\
\text { parameter }\end{array}$ & $\begin{array}{c}\text { Comments } \\
\text { (Experimental results in boldface type) }\end{array}$ \\
\hline \multirow[t]{4}{*}{1} & $\begin{array}{l}\text { wild type } \\
\text { (daughter) }\end{array}$ & 0.71 & $\begin{array}{l}1.07 \\
\left(71^{\prime}\right)\end{array}$ & $\begin{array}{r}1.15 \\
\left(84^{\prime}\right)\end{array}$ & $\begin{array}{l}1.15 \\
\left(84^{\prime}\right)\end{array}$ & $\begin{array}{r}1.64 \\
\left(146^{\prime}\right)\end{array}$ & 84 & & $\begin{array}{l}\text { CT } 146 \text { min } \\
\text { (time of occurrence of event) }\end{array}$ \\
\hline & 1st parent & 0.93 & 1.07 & 1.17 & 1.16 & 1.67 & 39 & & CT $101 \mathrm{~min}$ \\
\hline & 2nd parent & 0.95 & 1.08 & 1.18 & 1.17 & 1.68 & 37 & & СТ $99 \mathrm{~min}$ \\
\hline & 3rd parent & 0.96 & 1.08 & 1.18 & 1.17 & 1.69 & 36 & & CT $98 \mathrm{~min}$ \\
\hline 2 & $\ln 3^{1}$ & 1.24 & 2.04 & 2.20 & 2.15 & 2.88 & 99 & $D_{\mathrm{n} 3}=0$ & Dirick, 1995, Fig. 3 , size $1.7 \times W T$ \\
\hline 3 & $\operatorname{cln} 3 \operatorname{sic} 1$ & 1.09 & 1.85 & 1.28 & 1.90 & 2.54 & 28 & $\begin{aligned} D_{\mathrm{n} 3} & =0 \\
k_{\mathrm{s}, 1}^{\prime} & =0 \\
k_{\mathrm{s}, \mathrm{c} 1}^{\prime \prime} & =0\end{aligned}$ & G1 short, size $1.5 \times \mathrm{WT}$, smaller than $\operatorname{cln} 3$ \\
\hline \multirow[t]{2}{*}{4} & $C L N 3^{D}$ & 0.44 & 0.45 & 0.49 & 0.52 & 1.02 & 17 & $D_{\mathrm{n} 3}=8$ & $\begin{array}{l}\text { Yaglom, 1995, protein } 8 \times \text {, size } 75 \% \text { WT } \\
\text { Cross, 1988, Fig. 3, Nash, 1988, Fig. 1, size } \\
60 \% \text { WT }\end{array}$ \\
\hline & $\operatorname{cln} 3$ GAL-CLN3 & 0.43 & 0.43 & 0.46 & 0.50 & 0.99 & 14 & $D_{\mathrm{n} 3}=20$ & $\begin{array}{l}\text { Tyers, 1992, Table 1, protein } 20 \times \mathrm{WT} \text {, size } \\
44 \% \text { WT }\end{array}$ \\
\hline \multirow[t]{2}{*}{5} & $\begin{array}{l}\operatorname{cln} 3 \text { GAL-CLN3 } \\
\text { sic1 }\end{array}$ & 0.42 & 0.42 & 0.45 & 0.49 & 0.98 & 12 & $D_{\mathrm{n} 3}=20$ & SBF activated early, G1 short, cells small \\
\hline & & & & & & & & $\begin{array}{l}k_{\mathrm{s}, \mathrm{c} 1}^{\prime}=0 \\
k_{\mathrm{s}, \mathrm{c} 1}^{\prime \prime}=0\end{array}$ & \\
\hline 6 & $\operatorname{cln} 1 \operatorname{cln} 2$ & 1.46 & 1.47 & 2.47 & 2.58 & 3.39 & 91 & $k_{\mathrm{s}, \mathrm{n} 2}^{\prime \prime}=0$ & Dirick, 1995, Fig. 3 , size $3.2 \times W T$ \\
\hline 7 & $\operatorname{cln} 1 \operatorname{cln} 2 \operatorname{sic} 1$ & 0.81 & 1.12 & 0.97 & 1.29 & 1.89 & 31 & $k_{\mathrm{s}, \mathrm{n} 2}^{\prime \prime \prime}=0$ & $\begin{array}{l}\text { Dirick, 1995, Fig. 4, size between } c \ln 1 c \ln 2 \\
\text { and WT }\end{array}$ \\
\hline 8 & $\begin{array}{l}c \ln 1 \operatorname{cln} 2 \\
\text { clb5 clb6 }\end{array}$ & 0.71 & 1.23 & [11.66] & No bud & [14.44] & & $\begin{aligned} k_{\mathrm{s}, \mathrm{c} 1}^{\prime} & =0 \\
k_{\mathrm{s}, \mathrm{c} 1}^{\prime \prime} & =0 \\
k_{\mathrm{s}, \mathrm{n} 2}^{\prime \prime} & =0 \\
k_{\mathrm{s}, \mathrm{b} 5}^{\prime} & =0\end{aligned}$ & $\begin{array}{l}\text { Schwob, 1993, Fig. } 5 \text {, G1 arrest } \\
\text { We consider cells arrested in G1 if mass at } \\
\text { DNA replication exceeds } 5\end{array}$ \\
\hline 9 & $\begin{array}{l}c \ln 1 \operatorname{cln} 2 \\
G A L-C L N 2\end{array}$ & 0.34 & $\begin{array}{c}0.34 \\
\left(1^{\prime}\right)\end{array}$ & $\begin{array}{r}0.38 \\
\left(23^{\prime}\right)\end{array}$ & $\begin{array}{l}0.35 \\
\left(6^{\prime}\right)\end{array}$ & $\begin{array}{r}0.78 \\
\left(146^{\prime}\right)\end{array}$ & 23 & $\begin{array}{l}k_{\mathrm{s}, \mathrm{b} 5}^{\prime \prime}=0 \\
k_{\mathrm{s}, \mathrm{n} 2}=0.1 \\
k_{\mathrm{s}, \mathrm{n} 2}^{\prime \prime}=0\end{array}$ & $\begin{array}{l}\text { Dirick, 1995, Fig. } 6 \text {, size small, budding is } \\
\text { advanced more than DNA replication when } \\
\text { compared with WT }\end{array}$ \\
\hline 10 & $\begin{array}{l}\operatorname{cln} 1 \operatorname{cln} 2 \\
G A L-C L N 2 \operatorname{sic} 1\end{array}$ & 0.33 & 0.33 & 0.36 & 0.34 & 0.76 & 19 & $\begin{aligned} k_{\mathrm{s}, \mathrm{n} 2}^{\prime} & =0.1 \\
k_{\mathrm{s}, \mathrm{n} 2}^{\prime \prime} & =0 \\
k_{\mathrm{s}, \mathrm{c} 1}^{\prime} & =0 \\
k_{\mathrm{s}, c 1}^{\prime \prime} & =0\end{aligned}$ & SBF activated early, G1 short, cells small. \\
\hline 11 & $\begin{array}{l}c \ln 1 \operatorname{cln} 2 \\
M E T-C L N 2 \\
G A L-S I C 1\end{array}$ & 0.39 & 0.39 & 0.48 & 0.40 & 0.90 & 38 & $\begin{aligned} k_{\mathrm{s}, \mathrm{n} 2}^{\mathrm{s}, \mathrm{c}} & =0.1 \\
k_{\mathrm{s}, \mathrm{n} 2}^{\prime \prime} & =0 \\
k_{\mathrm{s}, \mathrm{c} 1}^{\prime} & =0.1 \\
k_{\mathrm{s}, \mathrm{c} 1}^{\prime \prime} & =0\end{aligned}$ & $\begin{array}{l}\text { Birth size between GAL-CLN2 and GAL-SIC1 } \\
(0.80)\end{array}$ \\
\hline 12 & $\begin{array}{l}c \ln 1 \text { cln2 } \\
M E T-C L N 2 \\
\text { clb1 clb2 } \\
\text { GAL-CLB2 }\end{array}$ & 0.20 & No SBF & 0.33 & 0.22 & 0.47 & 85 & $\begin{aligned} k_{\mathrm{s}, \mathrm{n} 2}^{\prime} & =0.1 \\
k_{\mathrm{s}, \mathrm{n} 2}^{\prime} & =0 \\
k_{\mathrm{s}, \mathrm{b} 2} & =0.1 \\
k_{\mathrm{s}, \mathrm{b} 2}^{\prime \prime} & =0\end{aligned}$ & $\begin{array}{l}\text { Steady-state mass at birth }=0.20(28 \% \text { WT }) \\
\text { cells may not be viable at this size. See Fig. } 7\end{array}$ \\
\hline
\end{tabular}

Note: to simulate mutants that synthesize cyclins constitutively, e.g., $\operatorname{cln} 1 c \ln 2$ GAL-CLN2, we set the rate constant for regulated synthesis to zero $\left(k_{\mathrm{s}}^{\prime \prime}=0\right)$ and the rate constant for unregulated synthesis to a uniform value $\left(k_{\mathrm{s}}^{\prime}=0.1\right)$ to represent a constant rate of expression from the $G A L$ promoter. This is a neutral assumption, in the absence of any quantitative data about levels of mRNA expression driven by the GAL promoter.

Cln3 contribute about equally to SBF activation. Simulations of the experiments of Dirick et al. (1995) are presented in Figure 6, A-C.

In the $\ln 1 \ln 2$ strain (Figure 6B), the events that normally occur together at Start are dissociated. First, SBF turns on at mass $=1.2($ volume $=24 \mathrm{fl})$, slightly larger than in wild-type cells $(22 \mathrm{fl})$. (We use the conversion factor 1 mass unit $=20$ fl.) Because $C \ln 1$ and $C \ln 2$ are missing, Sic1 degradation and Hct1 inactivation are delayed. Cells must grow larger $(\sim 35$ fl) before the combined effects of $\mathrm{Cln} 3$ and $\mathrm{Clb} 5$ can remove Sic1 (Cln3 phosphorylates and destabilizes Sic1, whereas Clb5 titrates away Sic1). With Sic1 gone, the rapidly rising
Clb5-associated kinase activity initiates DNA synthesis, bud emergence, and Hct1 inactivation. Then, as Clb2 appears, cells enter mitosis.

Start events in the $\operatorname{cln} 3$ strain (Figure 6C) occur at even larger size, because these cells rely on Bck2 alone to activate SBF. Once SBF turns on (at $\sim 41 \mathrm{fl}$ ), subsequent events of the cell cycle occur normally.

Properties of cln Mutants. When cycling, recessive cln3 mutant cells are $75 \%$ larger than wild-type cells, whereas dominant $C L N 3^{\mathrm{D}}$ mutant cells are $40 \%$ smaller, and double 


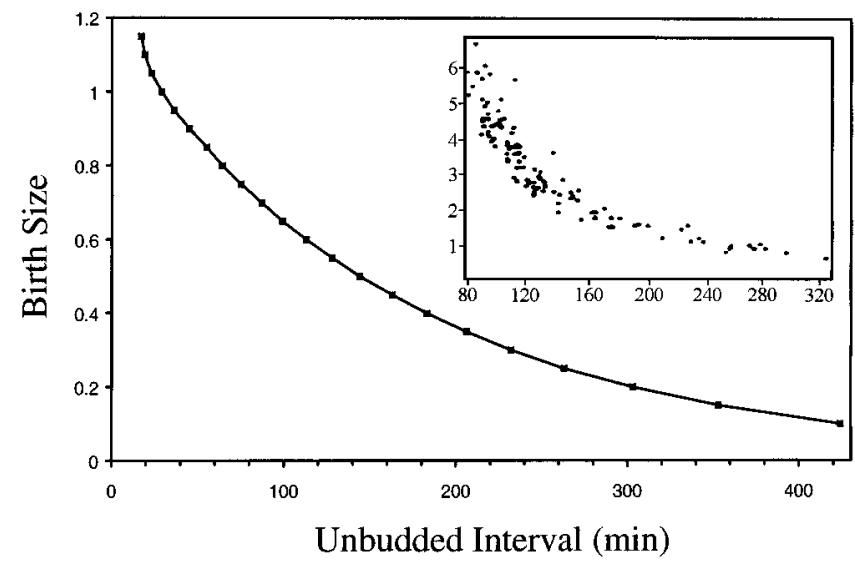

Figure 4. Length of the unbudded interval of daughter cells depends inversely on birth size. Inset, experimental results from Figure 5 of Johnston et al. (1977), used by permission.

recessive $\operatorname{cln} 1 \operatorname{cln} 2$ mutant cells are twice as large, all in agreement with observations (Table 3, lines 2, 4, and 6; Cross, 1988; Nash et al., 1988; Dirick et al., 1995).

In the paper by Dirick et al. (1995), the authors reported an intriguing phenomenon. As previously described, $\operatorname{cln} 1 \operatorname{cln} 2$ mutants, when started very small (10 fl), initiate DNA synthesis and budding at $\sim 40 \mathrm{fl}$ (their Figure 4 ). However, in cycling $\operatorname{cn} 1$ cln 2 cells, DNA synthesis and budding is delayed further to $60 \mathrm{fl}$ (their Figure 3). That is, although the birth size of the cycling cells is $\sim 32 \mathrm{fl}$, they are unable to initiate DNA synthesis and budding at $40 \mathrm{fl}$ but have to grow larger still $(60 \mathrm{fl})$ to do these jobs. Why?

Our simulation (Figure 6D) gives an explanation. In the cycling culture, when cells reach $40 \mathrm{fl}$ (which occurs soon after birth), there is still abundant Sic1, because Swi5 is active in early G1, and Sic1 degradation is slow in the absence of $C \ln 2$. It takes $\sim 1 \mathrm{~h}$ to remove Sic 1 by a combination of Cln3-dependent phosphorylation of Sic1 and Clb5 binding to Sic1. As soon as $[\mathrm{Clb} 5]_{\mathrm{T}} \approx[\mathrm{Sic} 1]_{\mathrm{T}}$, Clb5-depen-

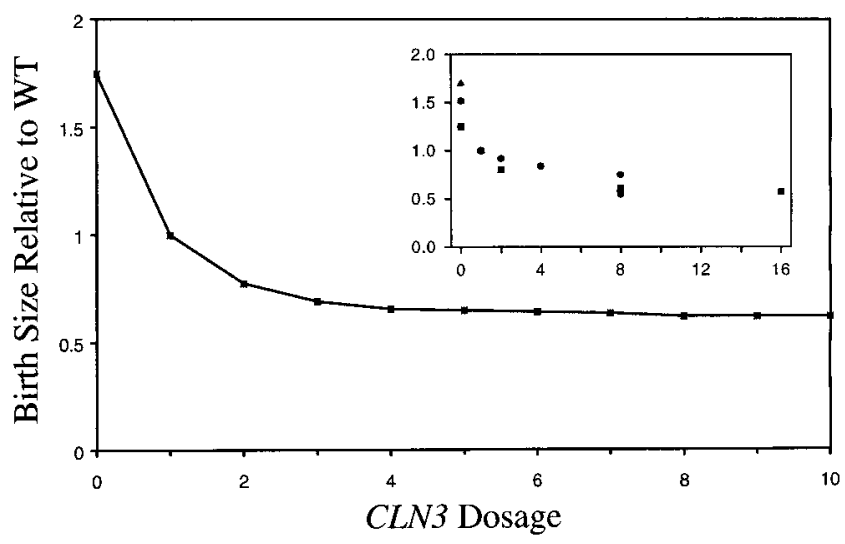

Figure 5. Dependence of cell size on CLN3 dosage. Inset, experimental results compiled from Cross (1988), Dirick et al. (1995), Nash et al. (1988), and Yaglom et al. (1995). dent kinase activity starts to rise and initiates DNA synthesis. In our simulation, cycling $\operatorname{cln} 1 \operatorname{cln} 2$ cells (born at mass $=$ $1.46,29 \mathrm{fl}$ ) begin DNA synthesis at mass $=2.47$ (Table 3, line 6 , equivalent to $49 \mathrm{fl}$ ); whereas for very small cells (born at mass $=0.71,14 \mathrm{fl})$, DNA synthesis begins at mass $=1.75$, equivalent to $35 \mathrm{fl}$. These results are in reasonable agreement with the observations of Dirick et al. (1995). Without the help of $\mathrm{Clb} 5$, as in the case of the $\operatorname{cln} 1 \mathrm{cln} 2 \mathrm{clb} 5 \mathrm{clb} 6$ mutant, Cln3-dependent kinase has a hard time fighting against Sic1 alone, and cells are inviable, blocked in G1 (Table 3, line 8).

When $C \ln 2$ is synthesized constitutively ( $\ln 1 \operatorname{cln} 2$ GALCLN2; Table 3, line 9), cells are smaller than normal. Because Cln2-dependent kinase activity is always high, Start occurs shortly after division, and size control at the G1/S transition is lost. Nonetheless, this strain is perfectly viable, and its cell cycle is still size regulated. As pointed out by Futcher (1996), this observation implies a size control mechanism in $\mathrm{M}$ phase that is cryptic as long as size control at Start is operating. In our model, this stems largely from the mass dependence of the positive feedback loop that activates Clb2 transcription. In small cells, the rise of $\mathrm{Clb} 2$-dependent kinase activity is delayed, which lengthens the duration of $M$ phase. Bypassing transcriptional control of $\mathrm{Clb} 2$ can test this explanation: cells constitutively expressing both $\mathrm{Cln} 2$ and Clb2 (cln1 cln2 MET-CLN2 clb1 clb2 GAL-CLB2) should be considerably smaller than cells constitutively expressing Cln2 alone $(\ln 1 \operatorname{cln} 2$ MET-CLN2) (Figure 7 and Table 3, lines 9 and 12). Such small cells may be inviable.

Rescue of Triple-cln Mutant. Especially noteworthy is the inviable triple-cln mutant $\operatorname{cln} 1 \operatorname{cln} 2 \operatorname{cln} 3$ (Table 4, line 2). $\mathrm{SBF}$ is activated by Bck2 (at a larger than normal size), but no other events of Start occur, because they all require CDK activity (the Clns are all missing, and the Clbs are all inhibited by Sic1). In our simulations, the cell eventually grows large enough for the low, G1 level of Clb5 to turn off Hct1 and Sic1 and then to initiate DNA synthesis and progress toward mitosis, but S/M commences at such a large size, 5 times larger than in wild-type, that the cell, we assume, has already died.

Clearly, the triple-cln mutant can be rescued by supplying CLN2 or CLN3 on a plasmid with a GAL promoter (Table 4, lines 3 and 4). It can also be rescued by GAL-CLB5 (Table 4, line 6) or simply by providing an extra genomic copy of CLB5 (Table 4, line 6), as observed (Epstein and Cross, 1992). In the latter case, Clb5 is made twice as fast, so cells are able to turn off Sic1 and Hct1 at a reasonable size. In addition, triple $c l n$ can be rescued by deleting the genomic copy of SIC1 (Schneider et al., 1996; Tyers, 1996) (see Figure 6F and Table 4, line 8; the mechanism for the rescue will be described later).

However, triple-cln mutants cannot be rescued by GALCLB2 (Table 4, line 7); cells remain arrested in G1 because active Hct1/APC keeps Clb2 level low (Amon et al., 1994). Nor can it be rescued by hct1 or apc mutations (Table 4, lines 9 and 10), as observed (Irniger and Nasmyth, 1997; Schwab et al., 1997); here DNA synthesis can be initiated, but cells cannot exit from mitosis (more on this later).

Role of Bck2. Bck2 has not received much attention from molecular biologists, but what is known (Epstein and Cross, 1994; Di Como et al., 1995) is consistent with the role given 

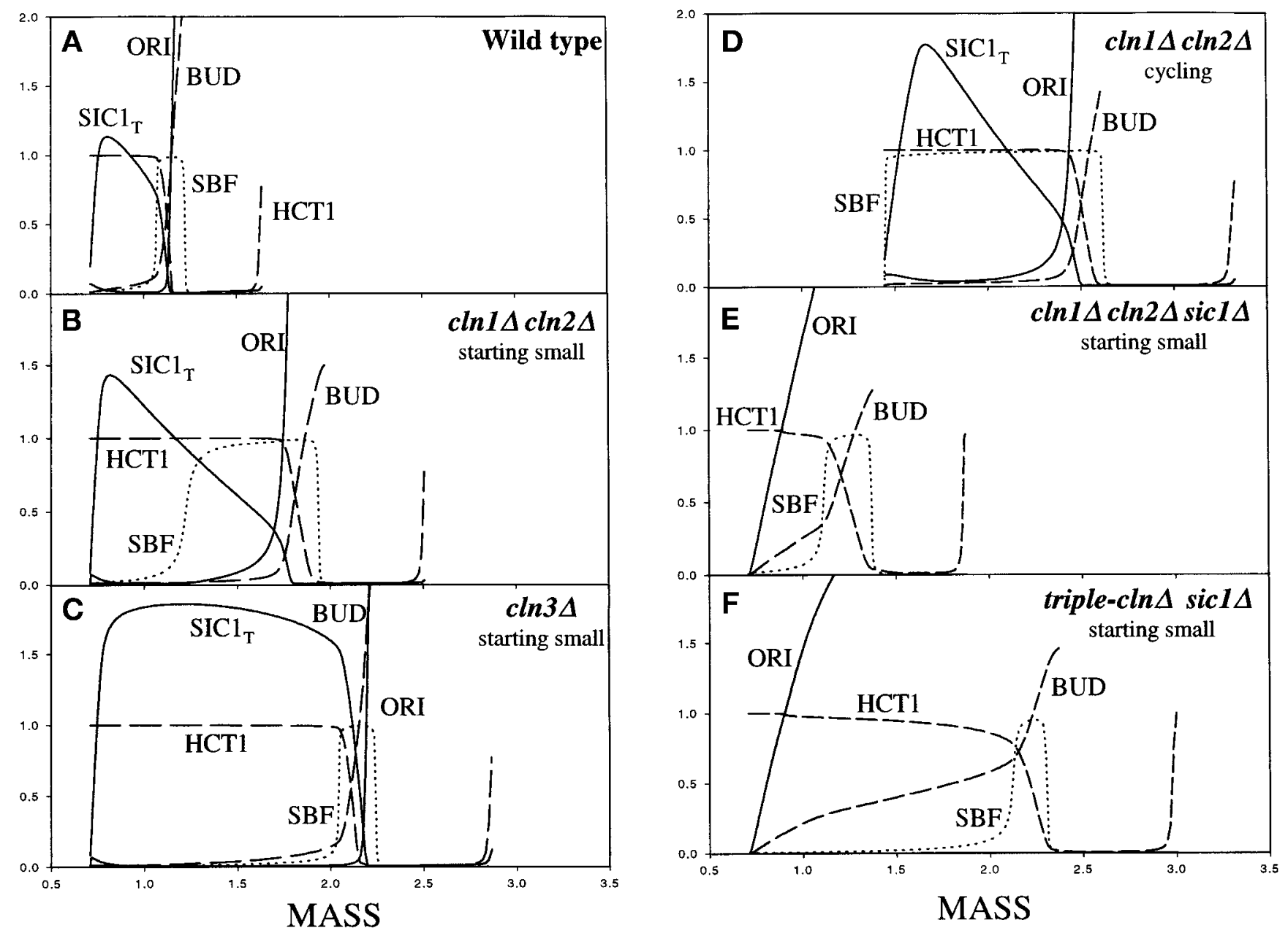

Figure 6. Dissociation of Start events in cln mutants. (A-C) Compare with experiments of Dirick et al. (1995). (A) In wild-type cells, several molecular and physiological events occur together at Start: activation of SBF, inactivation of Hct1, proteolysis of Sic1, initiation of DNA synthesis, and emergence of a bud. (B) In $\ln 1 \Delta \operatorname{cln} 2 \Delta$ cells, these events are dissociated: SBF is activated at wild-type size, but all other events are delayed until the cell gets much larger. (C) In $\ln 3 \Delta$ cells, the events are again concurrent, but they occur at about twice the size of wild-type cells. (D) Under steady-state conditions, $\ln 1 \Delta \operatorname{cln} 2 \Delta$ cells are much larger than wild type. SBF is activated immediately. However, DNA synthesis is much delayed (to mass $=2.47$ ), beyond the size at which it would occur (at mass $=1.75$ ) in B. This delay is due to the burst of Sic1 synthesis at anaphase. (E) Deletion of SIC1 from $\ln 1 \Delta \ln 2 \Delta$ suppresses the delay of bud emergence, as observed by Dirick (1995), and pushes DNA synthesis to a size smaller than in wild-type (contrary to their observation). In the absence of inhibitor, the small level of Clb5 early in the cycle is effective in driving DNA synthesis and bud emergence. See text for further discussion. (F) Deletion of SIC1 rescues the inviable $\ln 1 \Delta \operatorname{cln} 2 \Delta \ln 3 \Delta$ mutant. DNA synthesis begins at a small size (smaller than in wild type, as observed by Schneider $e$ et al., 1996), but all other events of Start are displaced to large size.

to Bck2 in the model (assumption 4). As for the case of CLN3 mutants, cells overexpressing BCK2 are smaller than normal $(66 \%)$, and bck2 loss-of-function mutants are larger than normal (180\%) (Table 5, lines $1 \mathrm{~b}$ and 1c). Although the triple mutant $\operatorname{cln} 1 \operatorname{cln} 2$ bck2 (line $2 \mathrm{~b}$ ) is viable and a little larger than $\operatorname{cln} 1 \quad \ln 2$, the double mutant $\operatorname{cln} 3$ bck2 (line $3 b$ ) is inviable: SBF is never activated, and cells arrest in G1. The inviable $\ln 3$ bck2 cell can be rescued, just like the triple-cln mutant, by GAL-CLN2, GAL-CLB5, or sic1 (lines 4a-4c). However, because SBF is not activated in this case, it takes more copies of genomic CLB5 (10 copies vs. 2) for its rescue (line $4 \mathrm{~d}$ ). Modest overproduction of Bck2 rescues triple-cln mutants (line 5b), provided both Swi4 and Swi6 are present, suggesting that Bck2 works through SBF.

Regulation of Clb Proteins. Because Start represents the commitment of a budding yeast cell to a new round of DNA synthesis and division, it is important that B-type cyclins (which drive $S$ phase and mitosis in budding yeast) be inoperative before Start occurs. The Clbs are kept out of the picture in G1 by three mechanisms: 1) CLB mRNA transcription is repressed, 2) $\mathrm{Clb}$ proteolysis by the APC is active, and 3) a Clb-dependent kinase inhibitor, Sic1, is abundant. In this section we explore the interrelations of 


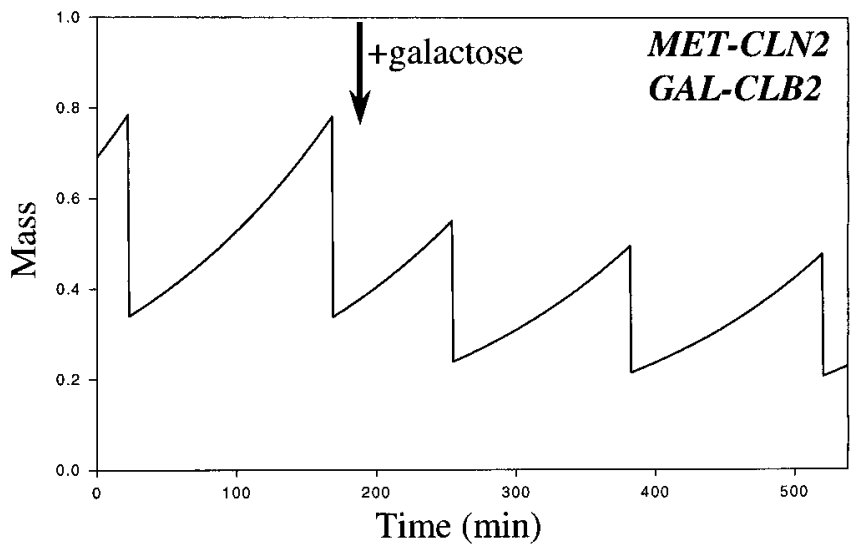

Figure 7. Simulation of MET-CLN2 GAL-CLB2 (no transcriptional control of $\mathrm{Cln} 2$ or $\mathrm{Clb} 2$ synthesis). In the absence of both methionine and galactose, cells are smaller than wild type, because Cln2 is synthesized constitutively. When galactose is added (arrow), cells get smaller still, eventually dividing at $\sim 30 \%$ of wild-type size. Such small cells may be inviable.

these three effects by simulating mutants that knock out the components singly and in combinations.

First of all, any one of these component processes is expendable. For instance, cells that synthesize $\mathrm{Clb} 2$ or $\mathrm{Clb} 5$ constitutively (clb1 clb2 GAL-CLB2 or clb5 clb6 GAL-CLB5) are viable (Table 6, lines 3 and 5, and Figure 8, top panel)
(Schwob and Nasmyth, 1993; Surana et al., 1993). GAL-CLB2 cells are nearly identical to wild-type because active Hct1/ APC keeps the Clb2 level low in G1. GAL-CLB5 cells have abnormally high levels of Clb5 in G1 phase, but abundant Sic1 inhibits the associated CDK activity. Start occurs on schedule when the cell grows large enough for Cln $3+$ Bck2 to activate SBF, which drives $C \ln 2$ accumulation and subsequent phosphorylation (and degradation) of Sic1.

Our model cell can tolerate overexpression of $\mathrm{Clb} 2$ better than Clb5. Up to three copies of GAL-CLB2 are tolerated; four copies or more lead to telophase arrest, as observed (Surana et al., 1993). Abnormally high levels of Clb2 can be tolerated because $\mathrm{Clb} 2$ induces its own degradation by stimulating Cdc20 synthesis (Prinz et al., 1998). Higher levels of Cdc20 effectively counteract higher levels of Clb2 at Finish. On the other hand, $2 \times G A L-C L B 5$ is lethal because Clb5associated kinase efficiently phosphorylates and destabilizes Sic1. As a consequence, Sic1 cannot make a comeback at Finish, Clb5/Cdc28 activity stays high, and DNA origins cannot be relicensed in G1.

The hct 1 mutant is also viable (Table 6, line 8, and Figure 8, middle panel) (Schwab et al., 1997). Normally, Clb2 is degraded at the metaphase-anaphase transition, but hct1 mutants finish the cell cycle differently. At anaphase, Cdc20 activates Swi5 and degrades some Clb2, allowing Sic1 to make a comeback and inhibit any remaining $\mathrm{Clb} 2$-dependent kinase activity. Subsequently, $\mathrm{Clb} 2$ protein level drops because its transcription turns off.

To model hct1 $\Delta$ mutants correctly, we must assume that Cdc20 accounts for some degradation of Clb2. Three lines of

Table 4. Mutations that rescue the $\operatorname{cln} 1 \operatorname{cln} 2 \operatorname{cln} 3$ strain

\begin{tabular}{|c|c|c|c|c|c|c|c|c|c|}
\hline & & $\begin{array}{l}\text { Mass at } \\
\text { birth }\end{array}$ & $\begin{array}{l}\text { Mass at } \\
\text { SBF } 50 \%\end{array}$ & $\begin{array}{l}\text { Mass at } \\
\text { DNA repl. }\end{array}$ & $\begin{array}{l}\text { Mass at } \\
\text { bud ini. }\end{array}$ & $\begin{array}{l}\text { Mass at } \\
\text { division }\end{array}$ & $\begin{array}{c}\mathrm{T}_{\mathrm{G} 1} \\
(\mathrm{~min})\end{array}$ & $\begin{array}{l}\text { Changed } \\
\text { parameter }\end{array}$ & $\begin{array}{c}\text { Comments } \\
\text { (Experimental results in boldface type) }\end{array}$ \\
\hline 1 & $\begin{array}{l}\text { wild type } \\
\text { (daughter) }\end{array}$ & 0.71 & $\begin{array}{l}1.07 \\
\left(71^{\prime}\right)\end{array}$ & $\begin{array}{l}1.15 \\
\left(84^{\prime}\right)\end{array}$ & $\begin{array}{l}1.15 \\
\left(84^{\prime}\right)\end{array}$ & $\begin{array}{c}1.64 \\
\left(146^{\prime}\right)\end{array}$ & 84 & & $\begin{array}{l}\text { CT } 146 \text { min } \\
\text { (time of occurrence of event) }\end{array}$ \\
\hline 2 & $\operatorname{cln} 1 \operatorname{cln} 2 \operatorname{cln} 3$ & 0.71 & 2.47 & [6.20] & [6.48] & [8.11] & & $\begin{aligned} D_{\mathrm{n} 3} & =0 \\
k_{\mathrm{s} n}^{\prime \prime} & =0\end{aligned}$ & Richardson, 1989, inviable \\
\hline 3 & $\begin{array}{l}\operatorname{cln} 1 \operatorname{cln} 2 \operatorname{cln} 3 \\
G A L-C L N 3\end{array}$ & 0.65 & 0.65 & 0.75 & 0.95 & 1.50 & 25 & $\begin{aligned} D_{\mathrm{s}, \mathrm{n} 2} & =20 \\
k_{\mathrm{s}, \mathrm{n} 2}^{\prime \prime} & =0\end{aligned}$ & $\begin{array}{l}\text { Schwob, 1993, Fig. 2, SBF activated soon } \\
\text { after galactose induction }\end{array}$ \\
\hline 4 & $\begin{array}{l}\operatorname{cln} 1 \operatorname{cln} 2 \operatorname{cln} 3 \\
G A L-C L N 2\end{array}$ & 0.34 & 0.34 & 0.39 & 0.35 & 0.79 & 25 & $\begin{aligned} D_{\mathrm{s}, \mathrm{n} 2} & =0 \\
k_{\mathrm{s}, \mathrm{n} 2}^{\prime} & =0.1 \\
k^{\prime \prime} & =0\end{aligned}$ & Cross, 1991, Fig. 4, GAL-CLN1 induces $c \ln 2$ \\
\hline 5 & $\begin{array}{l}\ln 1 \ln 2 \operatorname{cln} 3 \\
2 X C L B 5\end{array}$ & 2.81 & 2.83 & 4.96 & 5.15 & 6.52 & 98 & $\begin{aligned} D_{\mathrm{s}, \mathrm{n} 2} & =k_{\mathrm{s,n} 2}^{\prime \prime}=0 \\
k_{\mathrm{s}, \mathrm{b} 5}^{\prime} & =0.012 \\
k_{\mathrm{s}}^{\prime \prime} & =0.04\end{aligned}$ & Epstein, 1992, viable \\
\hline 6 & $\begin{array}{l}\operatorname{cln} 1 \operatorname{cln} 2 \operatorname{cln} 3 \\
G A L-C L B 5\end{array}$ & 1.23 & 2.07 & 2.05 & 2.14 & 2.86 & 88 & $\begin{aligned} D_{\mathrm{s} 3}, \mathrm{b5} & =k_{\mathrm{s}, \mathrm{n} 2}^{\prime \prime}=0 \\
k_{\mathrm{s}, \mathrm{b} 5}^{\prime} & =0.1 \\
k^{\prime \prime} & =0\end{aligned}$ & Schwob, 1993, Fig. 6, viable \\
\hline 7 & $\begin{array}{l}c \ln 1 \operatorname{cln} 2 \operatorname{cln} 3 \\
G A L-C L B 2\end{array}$ & 0.71 & 2.57 & [5.49] & [6.64] & [7.38] & & $\begin{aligned} k_{\mathrm{s}, \mathrm{b} 5} & =u \\
D_{\mathrm{n} 3} & =k_{\mathrm{s}, \mathrm{n} 2}^{\prime \prime}=0 \\
k_{\mathrm{s}, \mathrm{b} 2}^{\prime} & =0.1 \\
k_{\mathrm{s}, \mathrm{b} 2}^{\prime \prime} & =0\end{aligned}$ & $\begin{array}{l}\text { Amon, 1994, Fig. } 8 \text {, G1 arrest } \\
\text { We consider cells arrested in G1 if mass at } \\
\text { DNA replication exceeds } 5\end{array}$ \\
\hline 8 & $\begin{array}{l}\operatorname{cln} 1 \operatorname{cln} 2 \operatorname{cln} 3 \\
\quad \operatorname{sic} 1\end{array}$ & 1.30 & $\begin{array}{l}2.12 \\
\left(85^{\prime}\right)\end{array}$ & $\begin{array}{l}1.50 \\
\left(24^{\prime}\right)\end{array}$ & $\begin{array}{l}2.24 \\
\left(94^{\prime}\right)\end{array}$ & $\begin{array}{c}3.01 \\
\left(146^{\prime}\right)\end{array}$ & 24 & $\begin{aligned} D_{\mathrm{n} 3} & =k_{\mathrm{s}, \mathrm{n} 2}^{\prime \prime}=0 \\
k_{\mathrm{s}, \mathrm{c} 1}^{\prime} & =0 \\
k_{\mathrm{s}, \mathrm{c} 1}^{\prime \prime} & =0\end{aligned}$ & Tyers, 1996, Fig. 2, viable but large \\
\hline 9 & $\begin{array}{l}\operatorname{cln} 1 \operatorname{cln} 2 \operatorname{cln} 3 \\
h c t 1\end{array}$ & 0.71 & 2.48 & 4.62 & 5.03 & No mit & & $\begin{aligned} n_{\mathrm{s}, \mathrm{c} 1} & =k_{\mathrm{s,n} 2}^{\prime \prime}=0 \\
k_{\mathrm{d}, \mathrm{b} 2}^{\prime \prime} & =0.01\end{aligned}$ & Schwab, 1997, Fig. 3, M phase arrest \\
\hline 10 & $\begin{array}{l}\operatorname{cln} 1 \operatorname{cln} 2 \operatorname{cln} 3 \\
\text { apc-ts }\end{array}$ & 0.71 & 2.48 & 4.16 & 4.60 & No mit & & $\begin{aligned} D_{\mathrm{n} 3} & =k_{\mathrm{s}, \mathrm{n} 2}^{\prime \prime}=0 \\
k_{\mathrm{d}, \mathrm{b} 2}^{\prime \prime} & =0.01 \\
k_{\mathrm{d}, \mathrm{b} 2} & =0 \\
k_{\mathrm{d}, \mathrm{b} 5}^{\prime \prime} & =0\end{aligned}$ & Irniger, 1997, Fig. 2, M phase arrest \\
\hline
\end{tabular}


Cell size relative to wild type

\begin{tabular}{|c|c|c|c|c|c|}
\hline & & & & & \\
\hline & & & Observed & & \\
\hline Gen & & Epstein $^{a}$ & Di Como ${ }^{b}$ & Dirick $^{c}$ & Simulation \\
\hline $1 \mathrm{a}$ & CLN1 CLN2 CLN3 BCK2 & 1 & 1 & 1 & 1 \\
\hline $\mathrm{b}$ & $b c k 2$ & 1.3 & 1.5 & & 1.8 \\
\hline c & + low-copy BCK2 & & 0.8 & & 0.7 with 4 copies \\
\hline $2 \mathrm{a}$ & $\operatorname{cln} 1$ cln2 CLN3 BCK2 & 1.5 & & 3.2 & 2.1 \\
\hline $\mathrm{b}$ & $b c k 2$ & 1.7 & & & 2.6 \\
\hline $3 a$ & CLN1 CLN2 cln3 BCK2 & 1.7 & 1.5 & 1.7 & 1.7 \\
\hline $\mathrm{b}$ & $b c k 2$ & Inviable & Inviable & & Inviable \\
\hline $4 a$ & CLN1 CLN2 cln3 bck2 & & & & \\
\hline & $+G A L-C L N 2$ & & Rescued & & 0.5 \\
\hline $\mathrm{b}$ & + GAL-CLB5 & & & & 1.9 \\
\hline c & $+\operatorname{sic} 1$ & & & & 2.8 \\
\hline $\mathrm{d}$ & + low-copy CLB5 & & & & 3.7 with 10 copies \\
\hline $5 a$ & $\operatorname{cln} 1 \operatorname{cln} 2 \operatorname{cln} 3$ ВСК2 & Inviable & Inviable & & Inviable \\
\hline $\mathrm{b}$ & + low-copy BCK2 & Rescued & & & 3.9 with 4 copies \\
\hline
\end{tabular}

${ }^{a}$ Epstein and Cross (1994).

${ }^{b}$ Di Como et al. (1995).

${ }^{c}$ Dirick et al. (1995).

evidence support this assumption (10). Experiments of Irniger et al. (1995, their Figure 4) show that Clb2 is partially degraded in $c d c 15$ telophase-arrested cells when (we presume) Cdc20 is active and Hct1 is not. Visintin et al. (1997, their Figure 2) showed that $\mathrm{Clb} 2$ is degraded by both Hct1 and Cdc20 in nocodazole-arrested cells. Finally, it is well known that sister chromatid separation and B-type cyclin degradation are mediated by a single Cdc20 homologue during early embryogenesis of Drosophila and Xenopus (Dawson et al., 1995; Sigrist et al., 1995; Lorca et al., 1998).

The ability of Sic1 to bring Hct1-deficient cells out of mitosis depends on cell size: in the presence of $\alpha$-factor, hct1 cells grow very large, replicate their DNA, and block in mitosis (Schwab et al., 1997). Our simulation of $\operatorname{cn} 1 \operatorname{cln} 2 \operatorname{cln} 3$ hct1 behaves similarly (Table 6, line 9). By the time the mitotic checkpoint is satisfied and cells are ready to divide, they are so big and their accumulated Clb2 level is so high that Sic1 is unable to win over Clb2.

Although sic1 is sick (having many deficiencies in chromosome dynamics), it is still a viable mutant (Table 6, line 6, and Figure 8 , bottom panel). The only major change in the timing of cell cycle events is the advancement of DNA synthesis (relative to bud emergence) by $\sim 35 \mathrm{~min}$ (Schneider et al., 1996, their Figure 4). These authors show that sic1 cells initiate DNA synthesis at a much smaller size than wild-type cells.

Because in wild-type cells DNA synthesis and SBF activation occur almost concurrently, and SBF activation depends mainly on the actions of Cln3 and Bck2 (not inhibited by Sic1), it follows that in sic1 mutants initiation of DNA synthesis is well ahead of SBF activation. That is, the small amount of Clb5, synthesized by an MBF-independent pathway, is able to initiate DNA synthesis at a small size (because there is no Sic1 present to inhibit it), well before the cell is large enough to activate SBF.
In contrast to the viability of single mutants (GAL-CLBs, $h c t 1$, and sic1), double mutants are all inviable (Table 6, lines 9-13). hct1 sic1 cells, being unable to eliminate Clb2-dependent kinase, cannot exit mitosis (Visintin et al., 1997). clb5 GAL-CLB5 sic1 cells complete one cycle after adding galactose but die in the second cycle because they cannot replicate their DNA (they cannot resynthesize licensing factor, because $\mathrm{Clb}$-dependent kinase activity stays high after mitosis) (Schwob et al., 1994). clb2 GAL-CLB2 sic1 cells die after adding galactose, because they cannot bud (SBF is kept off by high $\mathrm{Clb} 2$-dependent kinase activity after mitosis). For the same reason, clb2 GAL-CLB2 hct1 and clb5 GAL-CLB5 hct1 cells are inviable.

Properties of SIC1 ${ }^{\text {op }}$ Mutants. Twofold overexpression of Sic1 is tolerated (Verma et al., 1997), but (roughly) 10-fold overexpression is deleterious (Nugroho and Mendenhall, 1994): some $20 \%$ of the cells have elongated buds and fail to divide. Our simulations of sic1 GAL-SIC1 (Table 6, line 7, with $k_{\mathrm{s}, \mathrm{c} 1}^{\prime \prime}=0$ and increasing $k_{\mathrm{s}, \mathrm{c} 1}$ up to fivefold from 0.1 to $0.5)$ give viable cells with increasing G1 period and larger sizes, but a sixfold increase is lethal (DNA synthesis commences at mass $>5$ ). This behavior is consistent with the experimental observations, provided cells in a population have a distribution of levels of Sic1 production. Similarly, cells with the phosphorylation sites of Sic1 removed (protein stable) never enter $S$ phase (Table 6, line 7), as observed (Verma et al., 1997).

The reason that cells tolerate high levels of Sic1 expression (i.e. $5 \times G A L-S I C 1)$ and still go through DNA synthesis and mitosis is because of the role played by CLN2. SBF activation is unaffected by Sic1; however, high levels of Sic1 inhibit Clb2 activity, so SBF inactivation is delayed. Cln2 will be synthesized at a high rate for longer time, and eventually 
Table 6. Properties of $c l b$, sic1, and hct1 mutants

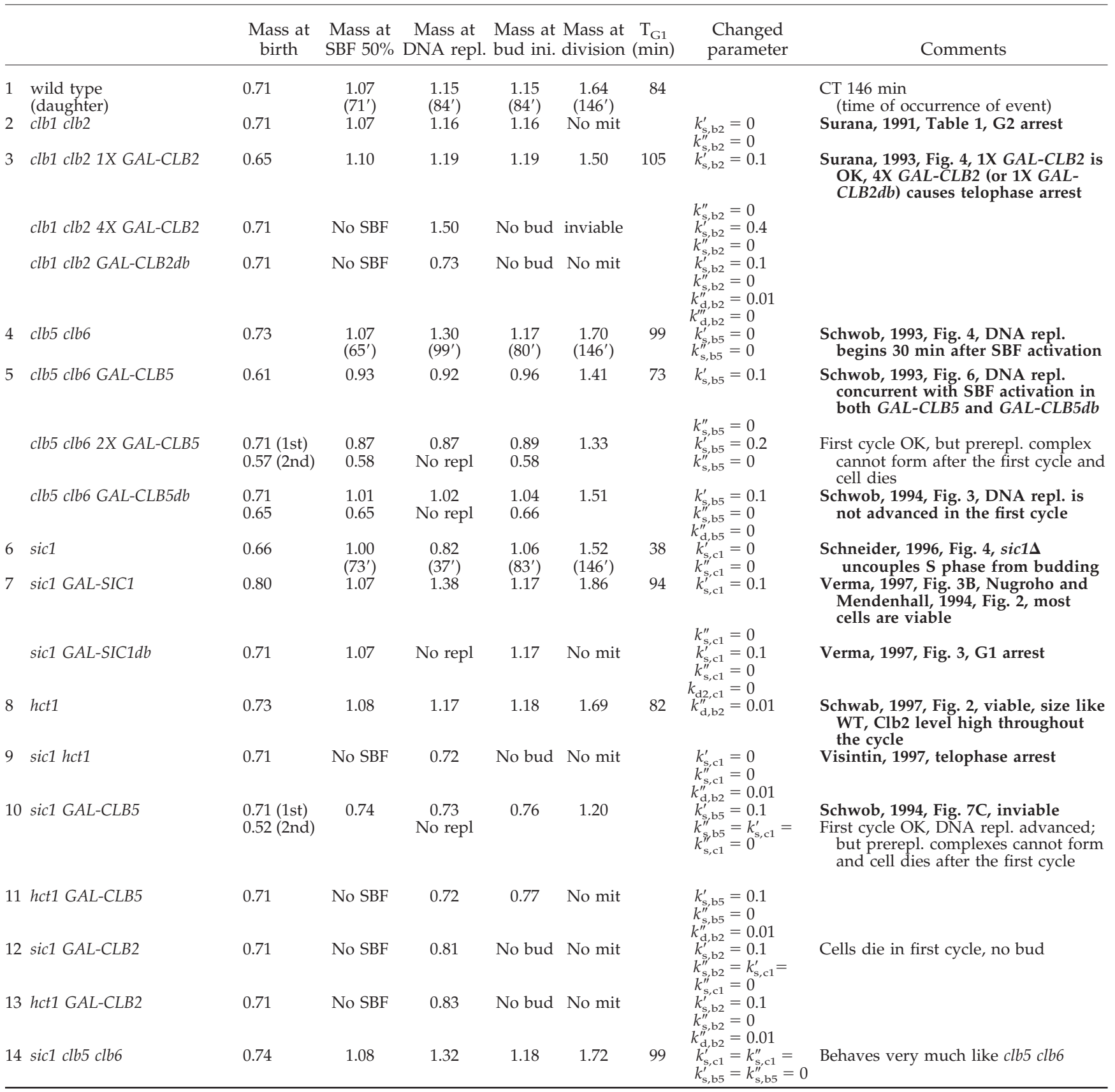

they will be able to phosphorylate Sic1, causing it to degrade and $\mathrm{Clb}$ kinases to win.

Initiation of DNA Synthesis in the sic1 Mutant. As described in the previous section, when compared with wild-type cells, sic1 mutants initiate S phase at a much smaller size, whereas $\operatorname{cln} 1 \operatorname{cln} 2$ mutants initiate it at a much larger size (Dirick et al., 1995). What will happen if the two mutations are combined?
Because, in sic1 mutants, initiation of DNA synthesis is driven mainly by the small amount of Clb5 present in early G1 cells, deletion of Clns should have little effect on its timing. Hence, the multiple mutants $\ln 1 \ln 2 \operatorname{sic} 1$ or $\ln 1 \ln 2 \ln 3 \operatorname{sic} 1$ all should initiate DNA synthesis at about the same size as the sic1 single mutant, at a size smaller than wild type.

Our simulation (Figure 6F) of $\operatorname{cln} 1 \operatorname{cln} 2 \operatorname{cln} 3 \operatorname{sic} 1$ agrees with observations of Schneider et al. (1996, their Figure 4B). Without Sic1 inhibition, Clb5 is able to initiate DNA synthesis early and 


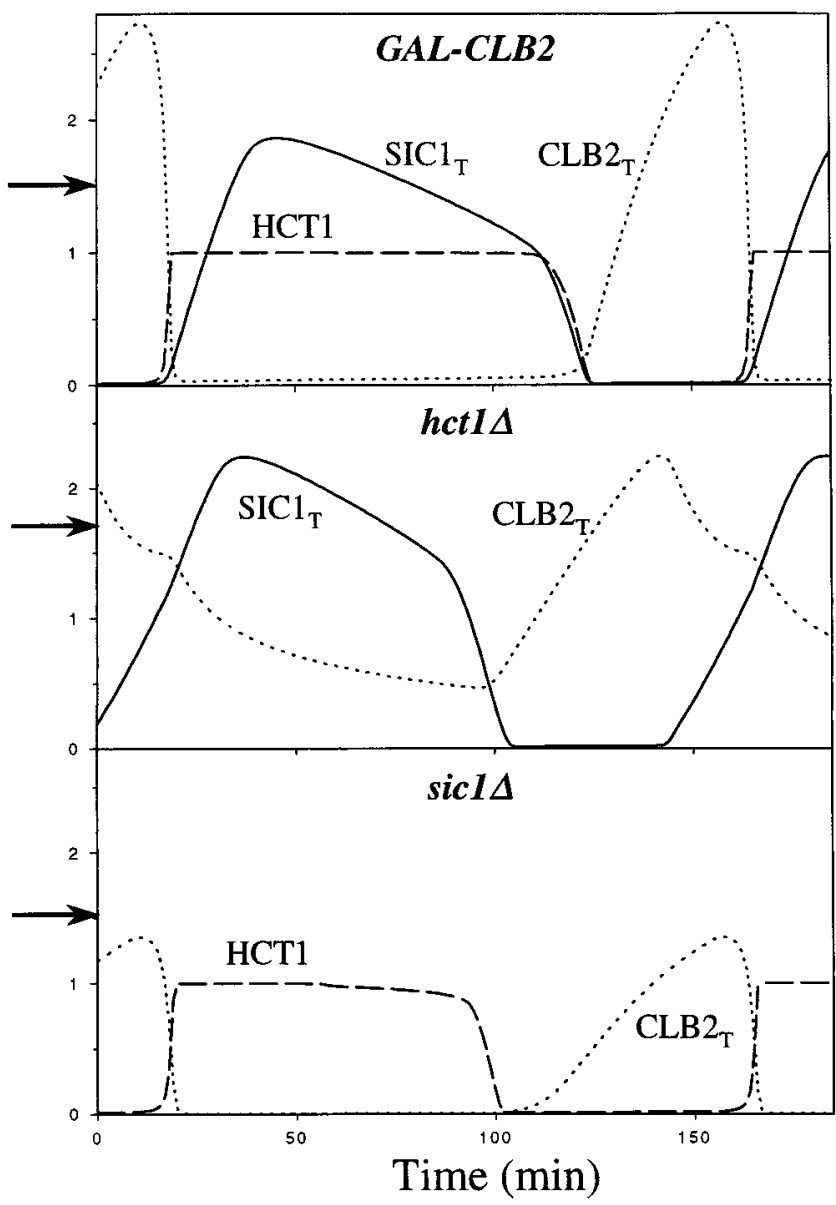

Figure 8. Cells are able to exit from mitosis when any single one of the three Clb2-inhibiting mechanisms is faulty. Top panel, constitutive transcription of CLB2 in G1 phase. Middle panel, no Hct1mediated degradation of $\mathrm{Clb} 2$ at telophase. Bottom panel, no Sic1 to inhibit Clb2/Cdc28 in G1 phase. The arrow on the ordinate indicates mass at division; all three strains have size comparable with wild type.

to help Bck2 turn on SBF and MBF, causing more Clb5 accumulation, Hct1 inactivation, and eventually progression toward mitosis.

However, for $\operatorname{cln} 1 \operatorname{cln} 2 \operatorname{sic} 1$, the simulation (Figure 6E) does not agree with observations. Dirick et al. (1995, their Figure 4) reported that DNA synthesis occurs at about the same size for the mutant as for wild-type cells. If the observation of Schneider et al. (1996) is true, then how can the addition of a functional CLN3 gene (giving $\operatorname{cln} 1 \operatorname{cln} 2 \operatorname{sic} 1$ ) delay DNA synthesis to a larger mass, when $C \ln 3$ is a helper to Clb5? Thus, we are unable to fit all these observations with our present understanding of the control system, and we believe that the experimental observation of Dirick et al. (1995) requires closer investigation.

\section{DISCUSSION}

In Figure 2, we propose a realistic mechanism for regulating the cell division cycle in budding yeast. Its components are
Cln1 and 2 (lumped together), Cln3 and Bck2, Clb1 and 2 (lumped), Clb5 and 6 (lumped), Sic1, Hct1 (=Cdh1), and Cdc20. (Cdc28, the kinase subunit that combines with the cyclins, is present in excess, so we need not keep track of its fluctuations.) In addition, the model tracks the relative activities of three transcription factors, Swi4/Swi6 (=SBF), Mcm1/SFF, and Swi5, which determine the rates of synthesis of $\mathrm{Cln} 2, \mathrm{Clb} 2$, and $\mathrm{Sic} 1$, respectively. At present, we assume that $\mathrm{MBF}$, the transcription factor for Clb5, is regulated coordinately with SBF. In the model, overall cell growth is exponential, and the basic events of the yeast division cycle (DNA synthesis, budding, and spindle assembly) are driven by the integrated activities of cyclin-dependent kinases. These assumptions lead to a mathematical model (Table 1) consisting of 10 nonlinear, ordinary differential equations (for mass, the cyclins, and their consorting proteins), three algebraic functions for transcription factors, three "integrators" to trigger DNA synthesis, budding, and spindle assembly, and a simple rule for separating mother and daughter cells at division.

The kinetic model introduces $\sim 50$ parameters (rate constants, binding constants, thresholds, relative efficiencies, etc.) that need to be determined by fitting specific experimental observations. For the present, we do this by trial and error (Appendix A), so we can only claim that our model equations and parameter set are sufficient to account for many properties of cell cycle control in budding yeast. Because we fit the model to the properties of dozens of different genotypes, we have enough data to fix the parameters and to provide meaningful confirmation of the mechanism in Figure 2.

Table 2 is in no sense an optimal parameter set, nor can we quantify how robust is the system, although our experience suggests that the model is quite hardy. Currently we are working on computational methods of parameter optimization and sensitivity analysis and hope to address these problems in a later publication.

\section{Bistability and Hysteresis}

The crucial idea behind our model of the budding yeast cell cycle is Nasmyth's (1996) hypothesis that G1 and S/M are alternative, self-maintaining states, generated by mutual antagonism between $\mathrm{Clb}$-dependent kinases and their opponents, Sic1 and Hct1. In theoretical terms, the molecular regulatory system exhibits bistability and hysteresis (Figure 9). In its "neutral" condition (no Cln2 or Cdc20), the control system can persist in either the stable G1 state or the stable $\mathrm{S} / \mathrm{M}$ state. Transitions between these alternative steady states can be driven by changes in $C \ln 2$ and Cdc20 that push the control system past the "fold" points in Figure 9 (Novak et al., 1998).

At Start, Cln2-dependent kinase activity rises abruptly and pushes the cell from G1 to S/M by inactivating Hct1 and promoting Sic1 degradation (Figure 9, stage $a$ ). The Clns can drive this transition because they are neither degraded by Hct1 nor inhibited by Sic1. After $\mathrm{Clb} 2$ appears, $\mathrm{Cln} 2$ is removed, but the cell remains in S/M because the Clbs can now keep Hct1 and Sic1 in abeyance without further help from Clns (stage $b$ ). This effect, called hysteresis, makes the Start transition irreversible.

Cdc20, activated at metaphase, pushes the cell from S/M to G1 (Finish) by activating Hct1 and promoting Sic1 accu- 


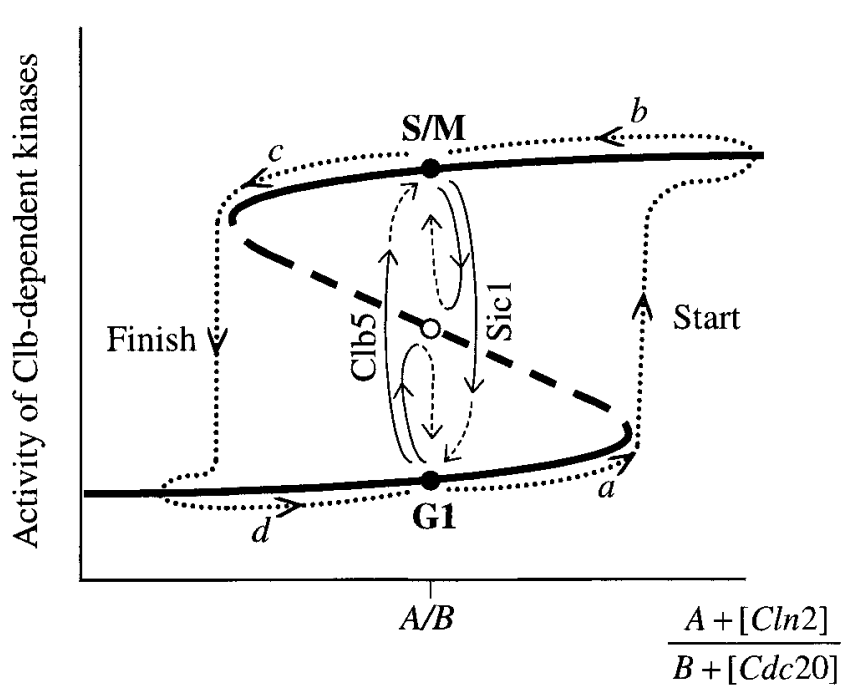

Figure 9. Bistability and hysteresis (schematic). Steady-state level of total $\mathrm{Clb}$-dependent kinase activity depends on the expression of CLN2 and CDC20. When [Cln2] is large and [Cdc20] is small, the Clb1-6 regulatory system is in a state of high kinase activity $(S / M)$, whereas in the other extreme, $\mathrm{Clb}$-dependent kinase activity is low (G1). When [Cln2] and [Cdc20] are both small, the regulatory system is in neutral (background activity $=A / B$ ), and two stable states of $\mathrm{Clb}$ activity coexist (bistability). The system is driven around a hysteresis loop (dashed curve) by pulses of $C \ln 2$ (stages $a$ and $b$ ) and Cdc20 (stages $c$ and $d$ ).

mulation (Figure 9, stage $c$ ). Cdc20 can drive this transition, because it is not opposed by Clb-dependent kinase activities; indeed, $\mathrm{Clb} 2$ promotes $\mathrm{Cdc} 20$ accumulation and activation. As Cdc20 is destroyed in G1 (stage $d$ ), the control system does not flip back to the S/M state, because Hct1 and Sic1 can now keep the Clbs in abeyance without further help from Cdc20. The S-shaped curve in Figure 9 accounts for the characteristic irreversibility of entry into $S$ phase and exit from mitosis.

In this picture, not merely may the "pushers" be removed and the control system will not revert, but they must be removed to make a repeated sequence of properly regulated Start and Finish transitions. For instance, once Start is accomplished, Cln2 must disappear; otherwise it will work against the Finish transition. Higher concentrations of Cdc20 will be required to trigger Finish. Furthermore, after the cell leaves mitosis, as Cdc20 disappears, Sic1 and Hct1 will not be able to hold the cell in G1. For these reasons, although GAL-CLN2 mutants are viable, they have short G1 and long $\mathrm{S} / \mathrm{M}$ periods.

Similarly, removal of Cdc20 after Finish is crucial for the next Start transition. Because the phosphatase (Cdc14) activated by Cdc20 can overwhelm all CDK activity at metaphase and thereby induce Finish, then it will be difficult to induce the next Start if Cdc20 activity does not disappear in G1 phase so that this phosphatase can be inactivated. In this regard, notice that mild overproduction of Cdc20 (GALCDC20 in $0.2 \%$ galactose) induces prolongation of G1 (Prinz et al., 1998), and strong overproduction (3X GAL-CDC20 in 2\% galactose) induces G1 arrest (Shirayama et al., 1998). GAL-CDC14 also induces G1 arrest (Visintin et al., 1998).
Direct experimental confirmation of bistability can be sought by holding the control system in neutral (Figure 9, position A/B) and then driving it between G1 and S/M by ectopic expression of Clb5 and Sic1 (Figure 9, vertical arrows). This experiment has been done in part by Dahmann et al. (1995). After arresting cells in mitosis with nocodazole, they induced transition to G1 (without nuclear or cell division) by ectopic expression of Sic1. When ectopic synthesis of Sic1 was repressed, their cells executed a second round of DNA synthesis, because endogenous production of Clns drove the cells through Start. To prevent autonomous reentry into $S$ phase, we suggest that cells be blocked with $\alpha$-factor as well as nocodazole.

We propose that a synchronous culture of MET-CLB5 TET-SIC1 cells (where MET = methionine-repressible promoter and TET = tetracyline-inducible promoter), about to execute Start and bud, be transferred from "growth" medium (containing methionine) to "arrest" medium (containing methionine, $\alpha$-factor, and nocodazole). (Notice that the use of $\alpha$-factor and nocodazole to arrest cells in neutral could be replaced by $\ln 1-3 \Delta$ and $c l b 1-4 \Delta$, respectively.) Those cells that have not yet executed Start when the medium is changed will be kept in G1 phase by $\alpha$ factor (moving from $a$ to G1 in Figure 9), whereas those cells that have already executed Start will be arrested in $\mathrm{M}$ phase by nocodazole (moving from $b$ to $\mathrm{S} / \mathrm{M}$ in Figure 9). The culture is now a mixed population of G1- and S/M-arrested cells, suggesting that, in this neutral position, there coexist two stable steady states of $\mathrm{Clb}$ activity. To prove the coexistence of these states, divide the culture into two batches. One batch is subjected to transient Clb5 synthesis by transferring the cells briefly to "Clb5" medium ( $\alpha$-factor + nocodazole) and then back to arrest medium. All cells in this batch are expected to arrest in the S/M state (in Figure 9, cells initially at G1 will be driven to $S / M$, whereas those initially at $S / M$ will return there). Cells of the other batch, after brief exposure to "Sic1" medium (methionine + tetracycline $+\alpha$-factor + nocodazole), are expected to arrest uniformly in G1 phase. Furthermore, the duration of the "brief" exposure is important: there should be threshold levels of exposure to Clb5 and Sic1 below which the transitions are not accomplished (see Figure 9).

Note that, at the end of treatment, all cells are of uniform size and are exposed to arrest medium. Nonetheless, if our model is correct, individual cells will be in different phases of the division cycle, depending on how they were perturbed. Those cells initially in G1 will be pushed into S/M by a Clb5 perturbation but not by a Sic1 perturbation (Schwob and Nasmyth, 1993) and vice versa for those cells initially in S/M (Dahmann et al., 1995). This behavior would indicate that two stable states of $\mathrm{Clb}$ activity coexist (bistability) when the regulatory system is in neutral. By alternating treatment with Clb5 and Sic1, one should be able to induce multiple rounds of endoreplication in $\operatorname{cln} 1-3 \Delta$ clb1-4s cells.

\section{Reversibility of the SBF Switch}

In contrast to the irreversibility of the Start and Finish transitions, the activation of SBF in our model is a reversible, ultrasensitive switch. To test this feature of the model, one could modify slightly the experimental design of Dirick et al. (1995). The strain $c \ln 1 \Delta c \ln 2 \Delta c \ln 3^{\text {ts }} M E T-C L N 2$ is grown in 
the absence of methionine, so that newborn daughter cells are small. Small cells, transferred to methionine-containing medium at permissive temperature, will activate SBF (measured by expression of PCL1 mRNA, say) at wild-type size, but Sic1 degradation and Hct1 activation will be delayed to a much larger size. If, after SBF activation, the cells are transferred to restrictive temperature, then SBF should inactivate (i.e., this event is reversible), and the cells should remain in G1.

\section{Autonomously Oscillating Versus Checkpoint- controlled Cell Cycles}

Cell division cycles of budding yeast (and somatic cells in general) are blocked by drugs that inhibit DNA replication or spindle assembly ("checkpoint controls"), whereas early embryonic cell divisions are unrestrained by these same drugs (Murray and Hunt, 1993). If somatic and embryonic cells use the same cell cycle control machinery, why do they behave so differently?

In theoretical terms, checkpoints correspond to stable steady states (G1 and S/M in the current model), and drugs that inhibit growth, DNA synthesis, or spindle assembly abort the signals that normally push the cell from one checkpoint to the next. The existence of these checkpoints depends on the mutual antagonism between cyclin B-dependent kinases and their opponents (Sic1 and Hct1 homologues).

In early Xenopus embryos, there are no effective antagonists of cyclin B/Cdc2 kinase (also called MPF). 1) The only identified MPF inhibitors are p28 $8^{\mathrm{Kix} 1}$ (Shou and Dunphy, 1996) and $\mathrm{p} 27^{\mathrm{Xic} 1}$ (Su et al., 1995), but both are present at very low levels until the late gastrula stage. Furthermore, neither one inhibits MPF in vitro. 2) XFZR (the Xenopus homologue of HCT1) is not translated before the midblastula transition. Instead, X-FZY (the Xenopus homologue of Cdc20) is responsible for cyclin B degradation during early embryonic cell cycles (Lorca et al., 1998). X-FZY, like Cdc20, seems to be activated rather than inhibited by MPF (Felix et al., 1990). 3) Even the antagonistic relationship between MPF and Wee1 (a tyrosine kinase that inhibits Cdc2) seems to be ineffective, because Cdc2 shows very little tyrosine 15 phosphorylation during the early cycles of intact embryos (Ferrell et al., 1991).

Without effective antagonists in early embryonic cells, MPF cannot establish the alternative steady states characteristic of checkpoint controls. The only remaining control is a time-delayed negative feedback loop, whereby MPF activates X-FZY, which degrades cyclin B and thereby destroys MPF activity. The sufficiency of this mechanism to generate autonomous oscillations in MPF activity was shown first by Goldbeter (1991) and later by Novak and Tyson (1993). Because the early embryo lacks cyclin B antagonists, it supports rapid MPF oscillations that are insensitive to errors in DNA replication and spindle assembly; apparently the early embryo has sacrificed accuracy for speed. However, in frog egg extracts, checkpoint control can be elicited if a sufficient amount of unreplicated sperm DNA is added (Dasso and Newport, 1990; Smythe and Newport, 1992), which creates an effective antagonist by activating Wee1. If our hypothesis is right, one may be able to elicit checkpoint responses in Xenopus embryos before the midblastula transition by injecting XFZR mRNA (or protein) into the fertilized egg.

\section{Models as Tools in Molecular Biology}

Undoubtedly the genetic regulatory system of cell division in yeast and higher eukaryotes is even more complex than Figure 2. To understand regulatory systems of such complexity, we need analytical tools that can handle realistic biochemical control mechanisms. Our work confirms that modern methods of kinetic theory and computation are capable of connecting a realistic, multilayered, regulatory mechanism to the complex physiological behavior of cells.

In addition to its role in synthesizing molecular and physiological details about cell division, the model is a predictive tool. The rate constant estimates in Table 2 can be tested by more direct kinetic measurements. Tables 3-6 specify many quantitative properties of mutant cells that have never been reported, and they predict phenotypes of several mutants yet to be examined.

One can learn as much from the failures of the model as from its successes. Where there are inconsistencies between the model and experiment, we are prompted, first of all, to look for a better parameter set. If that fails, we consider slight changes in the mechanism, which might bring the model in accord with observations. If that fails, and if the experimental community is convinced that the observations are reliable and significant, then we have identified an area that deserves closer scrutiny to resolve the discrepancies. If the mechanism proves insufficient, that does not invalidate our approach. Mathematical modeling, as a tool, is no more "falsifiable" than gel electrophoresis. The tool tells us what a mechanism can and cannot explain. When the model fails, the fault lies with the mechanism, not the tool.

The molecular mechanism of cell cycle control in budding yeast is an evolving hypothesis that must be continually examined, revised, and improved as new observations tell us more about the control system. We intend to extend the model in several directions. First, we will provide a more detailed description of Finish (Novak et al., 1999), including roles for Cdc14 (Visintin et al., 1998; Jaspersen et al., 1999), RENT complexes (Shou et al., 1999), and Pds1/Esp1 interactions (Ciosk et al., 1998; Cohen-Fix and Koshland, 1999; Tinker-Kulberg and Morgan, 1999). The next step will be to connect mathematical representations of surveillance mechanisms to the underlying cell cycle engine. For instance, the mating factor pathway connects pheromone binding at the cell surface, through a protein kinase cascade, to the inhibition of Cln kinases, which arrests cells before Start (Wittenberg and Reed, 1996; Posas et al., 1998). Another important signal transduction pathway, through mad and bub gene products, arrests cells in mitosis, if the mitotic spindle is improperly assembled (Alexandru et al., 1999; Taylor, 1999).

\section{APPENDIX A: ESTIMATION OF RATE CONSTANTS}

First some definitions:

1) A Michaelis constant ( $J$ in our notation) carries units of concentration (nM). In the Michaelis-Menten rate law, $J$ is the characteristic substrate concentration at which reaction rate is half-maximal.

2) A zero-order rate constant carries units of $\mathrm{nM} \mathrm{min}{ }^{-1}$. Examples include rates of synthesis ( $k_{\mathrm{s}}$ in our notation), and $\mathrm{V}_{\max }$ values in Michaelis-Menten rate laws $\left(k_{\mathrm{a}}\right.$ and $k_{\mathrm{i}}$ in our notation). 
3) A first-order rate constant carries units of $\min ^{-1}$. Examples include degradation rate constants $\left(k_{\mathrm{d}}\right)$ and dissociation rate constants $\left(k_{\mathrm{di}}\right)$.

4) A second-order rate constant, e.g., an association rate constant $\left(k_{\text {as }}\right)$, carries units of $\mathrm{nM}^{-1} \mathrm{~min}^{-1}$.

In writing the kinetic equations in Table 1, all concentration variables are scaled so that their maximal values are pure numbers of order 1 . We are forced to do this because little is known about the actual concentrations (nM) of any of the molecular components in budding yeast cells. Because all concentration variables are dimensionless, the Michaelis constants are dimensionless, and all the zero-, first-, and second-order rate constants carry units of $\min ^{-1}$ (Table 2).

\section{Rates of Degradation}

Because the stability of cyclins at various stages in the budding yeast cell cycle has been studied carefully by many experimental groups, we can estimate the cyclin degradation constants in our model with some confidence. For instance, the half-life Cln2 is 5-10 min (Salama et al., 1994; Barral et al., 1995; Lanker et al., 1996), implying that $k_{\mathrm{d}, \mathrm{n} 2} \approx \ln 2 / 7=0.1$ $\min ^{-1}$, which is the value we use (Table 2). Because Hct1 is turned off at Start, Clb2 is more stable in S/M than in G1: half-life = $1 \mathrm{~min}$ in G1 and > $1 \mathrm{~h}$ in S/M (Amon et al., 1994; Irniger et al., 1995; Seufert et al., 1995). These observations imply that $k_{\mathrm{d}, \mathrm{b} 2}^{\prime} \approx \ln 2 / 70=0.01 \mathrm{~min}^{-1}$ and $k_{\mathrm{d}, \mathrm{b} 2}^{\prime \prime} \approx \ln 2 / 1=$ $0.7 \mathrm{~min}^{-1}$, which are close to the values in Table 2. Clb5, on the other hand, is only slightly more stable in S/M (halflife $=10 \mathrm{~min}$ ) than in G1 (half-life $=2 \mathrm{~min}$ ) (Irniger and Nasmyth, 1997). Hence, $k_{\mathrm{d}, \mathrm{b} 5}^{\prime} \approx \ln 2 / 10=0.07 \mathrm{~min}^{-1}$, and $k_{\mathrm{d}, \mathrm{b} 5}^{\prime}+k_{\mathrm{d}, \mathrm{b} 5}^{\prime \prime} \approx \ln 2 / 2=0.35 \mathrm{~min}^{-1}$ (see Table 2).

From the observed half-life of Cdc20, 15 min (Shirayama et al., 1998), we estimate that $k_{\mathrm{d}, 20}=0.05 \mathrm{~min}^{-1}$.

Sic1 disappears at Start over the course of $\sim 20 \mathrm{~min}$ (Schwob et al., 1994). Because we use a Michaelis-Menten rate law for Sic1 phosphorylation (the rate-limiting step for Sic1 degradation at Start), it is not so obvious how to estimate our rate parameters, but the values $J_{\mathrm{d} 2, \mathrm{c} 1} \ll 1$ and $k_{\mathrm{d} 2, \mathrm{c} 1}$ $=0.3 \mathrm{~min}^{-1}$ give reasonable agreement to Schwob's observation.

\section{Rates of Synthesis}

Rate constants for cyclin synthesis can be estimated from degradation rate constants and steady-state concentrations. However, because the concentrations are unknown, we cannot ascribe directly meaningful values to the synthesis rate constants. Instead, we choose $k_{\mathrm{s}} \approx k_{\mathrm{d}}$, so that the maximum concentrations of all variables during a wild-type cycle are $\sim 1$. The chosen values of $k_{\mathrm{s}}$ reflect the relative concentrations of the cyclins, Sic1, and Cdc20, as best we can guess, but the arbitrary units (au) in which each concentration is expressed are unknown until we have better experimental data. For instance, suppose the peak concentrations of Sic1 and $C \ln 2$ were measured to be 100 and $30 \mathrm{nM}$, respectively. Then, from Figure 3, we would assign 1 au of Sic1 concentration $=90 \mathrm{nM}$ and 1 au of Cln2 concentration $=60 \mathrm{nM}$, and we could predict that ${k^{\prime}}_{\mathrm{s}, \mathrm{c} 1}=1.8 \mathrm{nM} \mathrm{min}^{-1}, k_{\mathrm{s}, \mathrm{c} 1}^{\prime \prime}=9$ $\mathrm{nM} \min ^{-1}$ (when Swi5 is fully active), $J_{\mathrm{d} 2, \mathrm{c} 1}=4.5 \mathrm{nM}$, and $k_{\mathrm{d} 2, \mathrm{c} 1}=0.3 \min ^{-1}(90 / 60 \mathrm{nM})=0.45 \mathrm{~min}^{-1}$.

\section{Rates of Association and Dissociation}

The rate constant $\left(k_{\mathrm{as}}\right)$ for association of Sic1 with $\mathrm{Clb} 2 /$ Cdc28 and $\mathrm{Clb} 5 / \mathrm{Cdc} 28$ is an important parameter in the model. It must be large enough to account for strong binding, given reasonable lability of the complexes $\left(k_{\mathrm{di}}=0.05\right.$ $\min ^{-1}$, assumed). We choose $k_{\text {as }}=50 \mathrm{~min}^{-1}$, which implies a binding constant of $10^{3}$. The theory of diffusion-controlled reactions (Tinoco et al., 1978, p. 385) puts an upper limit on second-order rate constants: $k_{\max }=8 \pi \mathrm{rN}_{\mathrm{o}} \mathrm{D}_{\text {avg }}$, where $\mathrm{r}=$ encounter distance of a pair of reacting molecules, $\mathrm{N}_{\mathrm{o}}=$ Avogadro's number, and $\mathrm{D}_{\text {avg }}=$ average diffusion coefficient of the reacting molecules. Assuming r $=4 \times 10^{-7} \mathrm{~cm}$, and $\mathrm{D}_{\text {avg }}=2 \times 10^{-6} \mathrm{~cm}^{2} \mathrm{~s}^{-1}$, we estimate that $k_{\max }=10^{10}$ $1 \mathrm{~mol}^{-1} \mathrm{~s}^{-1}=10 \mathrm{nM}^{-1} \mathrm{~s}^{-1}$. If the concentration of protein partners is roughly $80 \mathrm{nM}$, then $k_{\max }($ scaled $) \approx 5 \times 10^{4}$ $\mathrm{min}^{-1}$, which is 1000 times larger than the value assigned to $k_{\text {as. }}$.

\section{Rates of Activation and Inactivation}

The transcription factors SBF, Mcm1, and Swi5 are each described by Goldbeter-Koshland functions, $\mathrm{G}\left(V_{\mathrm{a}}, V_{\mathrm{i}}, J_{\mathrm{a}}, J_{\mathrm{i}}\right)$. (Please refer to Appendix B for the definition of this function and a detailed description of its properties.) When $J_{\mathrm{a}}$ and $J_{\mathrm{i}}$ are much less than 1, a Goldbeter-Koshland function changes very abruptly in the neighborhood of $G=1 / 2$. Because the SBF switch turns on abruptly as cells grow (Dirick et al., 1995), we choose $J_{\mathrm{a}, \mathrm{sbf}}$ and $J_{\mathrm{i} \text {,sbf }}$ to be small (0.01). By contrast, we suppose that Mcm1 turns on and off more smoothly $\left(J_{\mathrm{a}, \mathrm{mcm}}=J_{\mathrm{i}, \mathrm{mcm}}=1\right)$.

Activation and inactivation of Hct1 is also governed by a Goldbeter-Koshland mechanism, but we do not make a pseudo-steady-state approximation $(\mathrm{d}[\mathrm{Hct} 1] / \mathrm{dt}=0)$. Rather,

$$
\begin{aligned}
& \frac{\mathrm{d}}{\mathrm{dt}}[\mathrm{Hct} 1]=\frac{\left(k_{\mathrm{a}, t 1}^{\prime}+k_{\mathrm{a}, \mathrm{t}}^{\prime \prime}[\mathrm{Cdc} 20]\right) \cdot\left([\mathrm{Hct} 1]_{\mathrm{T}}-[\mathrm{Hct} 1]\right)}{J_{\mathrm{a}, \mathrm{t} 1}+[\mathrm{Hct} 1]_{\mathrm{T}}-[\mathrm{Hct} 1]} \\
& -\frac{\left\{k_{i, 11}^{\prime}+k_{\mathrm{i}, 11}^{\prime \prime}\left([\mathrm{Cln} 3]^{*}+\varepsilon_{\mathrm{i}, 1, \mathrm{n} 2}[\mathrm{Cln} 2]+\varepsilon_{\mathrm{i}, 1, \mathrm{~b} 5}[\mathrm{Clb} 5]+\varepsilon_{\mathrm{i}, \mathrm{1}, \mathrm{b} 2}[\mathrm{Clb} 2]\right)\right\}[\mathrm{Hct} 1]}{J_{\mathrm{i}, \mathrm{t} 1}+[\mathrm{Hct} 1]}
\end{aligned}
$$

The rates at which Hct1 switches between more and less active forms depend on the rate constants, $k_{\mathrm{a}}$ and $k_{\mathrm{i}}$. We expect they have values of order $1 \mathrm{~min}^{-1}$, so that changes occur in minutes rather than seconds or hours. More precise estimates cannot be made from presently available measurements.

To estimate the conditions for turning Hct1 on and off, we notice that $[$ Hct 1$] \approx 1 / 2[\text { Hct } 1]_{\mathrm{T}}$ when

$$
\begin{aligned}
k_{\mathrm{a}, \mathrm{t} 1}^{\prime}+k_{\mathrm{a}, \mathrm{t} 1}^{\prime \prime}[\mathrm{Cdc} 20]=k_{\mathrm{i}, \mathrm{t} 1}^{\prime}+k_{\mathrm{i}, \mathrm{t} 1}^{\prime \prime}\left([\mathrm{Cln} 3]^{*}+\varepsilon_{\mathrm{i}, \mathrm{t} 1, \mathrm{n} 2}[\mathrm{Cln} 2]\right. \\
\left.+\varepsilon_{\mathrm{i}, \mathrm{t} 1, \mathrm{~b} 5}[\mathrm{Clb} 5]+\varepsilon_{\mathrm{i}, \mathrm{t} 1, \mathrm{~b} 2}[\mathrm{Clb} 2]\right)
\end{aligned}
$$

(provided $J_{\mathrm{a}, \mathrm{t} 1}=J_{\mathrm{i}, \mathrm{t} 1}$ ). In metaphase, when $\mathrm{Clb} 2$ plays the major role in keeping Hct1 inactive, the condition for activating Hct1 is [Cdc20] $=k^{\prime \prime}{ }_{i, t 1}[\mathrm{Clb} 2] / k^{\prime \prime}{ }_{\mathrm{a}, \mathrm{t} 1} \approx 0.5$. That is, Hct1 turns on when Cdc20 activity exceeds $0.32 \times \mathrm{Clb} 2$ activity. The threshold can be adjusted by changing the ratio $k_{\mathrm{i}, \mathrm{t} 1}^{\prime \prime} / \mathrm{k}_{\mathrm{a}, \mathrm{t} 1}$. In late G1 phase, when [Cdc20] $\approx 0.05,[\mathrm{Clb} 2] \approx$ $0,[\mathrm{Cln} 3]^{*} \ll[\mathrm{Cln} 2]$, and Clb5 is still inhibited by Sic1, the condition for inactivating Hct1 is [Cln2] $=\left(k_{a, t 1}^{\prime}+\right.$ $\left.k^{\prime \prime}{ }_{\mathrm{a}, \mathrm{t} 1}[\mathrm{Cdc} 20]\right) / k_{\mathrm{i}, \mathrm{t} 1}^{\prime \prime} \approx 0.2$. With our choice of parameters, Cln2 plays the major role in turning off Hct1 at Start. It may be that Clb5 plays a more important role, in which case the 
relative efficiencies $\left(\varepsilon_{\mathrm{i}, \mathrm{t} 1, \mathrm{~b} 5}\right.$ and $\left.\varepsilon_{\mathrm{i}, \mathrm{t} 1, \mathrm{n} 2}\right)$ would have to be readjusted.

\section{Other Parameters}

$[\mathrm{Cln} 3]_{\max }=0.02$ is chosen so that the amount of $\mathrm{Cln} 3$ at Start, $[\mathrm{Cln} 3]^{*} \approx 0.003$ when mass $\approx 1$, is $\sim 100$ times smaller than the maximum amounts of $C \ln 1$ and $C \ln 2$ during the cycle (Tyers et al., 1993). Although Cln3 is present in a very small amount, it plays an important role turning on SBF at Start (Dirick et al., 1995; Stuart and Wittenberg, 1995), because $\varepsilon_{\mathrm{sbf}, \mathrm{n} 3}$ is very large. [Bck2] ${ }^{0}=0.0027$ is chosen to account for the observed size for SBF activation in the $\ln 3$ mutant.

\section{Efficiencies}

Our model contains many other dimensionless "efficiencies" of different CDKs for various phosphorylation reactions. These efficiencies simply represent the fact that budding yeast cyclins have overlapping specificities: they often catalyze the same reactions but with different relative turnover numbers. We adjusted the efficiencies to account for the relative timing of events in mutants where the primary cyclin is missing and the event is triggered by one of its backups.

For instance, in triple-cln $\Delta$ sic $1 \Delta, \mathrm{Clb} 5$ is the primary cyclin responsible for Hct1 inactivation. If $\varepsilon_{\mathrm{i}, \mathrm{t} 1, \mathrm{~b} 5}$ were too small, then Hct1 would never turn off, and the mutant would be inviable. If $\varepsilon_{\mathrm{i}, \mathrm{t} 1 \mathrm{~b} 5}$ were too large, then the small amount of uninhibited Clb5 early in the cycle (which drives premature DNA synthesis in this mutant) would inactivate Hct1 too soon. As a result, $\mathrm{Clb} 2$ would rise early, and SBF could never be activated, so the mutant would divide at a small size without ever making a bud. In our simulations, $\varepsilon_{\mathrm{i}, \mathrm{t} 1 \mathrm{~b}, \mathrm{~b}} \approx 0.5$ gives a correct phenotype to this mutant.

\section{Integrators}

Finally, we have introduced three "integrators" (ORI, BUD, and SPN), which determine when the events of 1) initiation of DNA synthesis, 2) bud emergence, and 3) chromosome alignment on the mitotic spindle will occur. Experiments show that 1) DNA synthesis can be initiated by Clbs but not by Clns (Schwob et al., 1994); 2) bud emergence can be driven by Clb5 as well as Clns (Schwob and Nasmyth, 1993), and 3) mitosis can be driven to completion only by $\mathrm{Clb} 1$ and Clb2 (Surana et al., 1991). These facts determine the forms taken by the integrators. The rate constants $\left(k_{\mathrm{s}, \text { ori }}, k_{\mathrm{s}, \mathrm{bud}}\right.$, and $\left.k_{\mathrm{s}, \mathrm{spn}}\right)$ and efficiencies are chosen to give the right timing of these events in various mutants.

Note that some parameters are introduced only for notational consistency (e.g., $k_{\mathrm{a}, \mathrm{sbf}}, k_{\mathrm{a}, \mathrm{mcm}}, k_{\mathrm{a}, \mathrm{swi}}$, and $k_{\mathrm{i}, \mathrm{t} 1}$ ) and are set equal to 1 or 0 in all computations. Other parameters are constrained to be identical (e.g., $J_{a} \ldots=J_{i}, \ldots$ ), to limit the scope of the problem. Therefore, we had $\sim 50$ parameters to estimate from the properties of $\sim 50$ different genotypes. Wild-type cells provide us with enough information to estimate more than half of these parameters. The remaining parameters are constrained by the properties of all the mutants we have simulated. Because each viable mutant gives us at least two pieces of information (relative size and G1 duration), we have much more data to fit than parameters to vary. Therefore, because the model accounts for so many facts (in quantitative detail wherever possible), we conclude that the molecular mechanism in Figure 2 is essentially correct.

\section{APPENDIX B: ZERO-ORDER ULTRASENSITIVITY}

We model the kinetic behavior of the budding yeast transcription factors (SBF, Mcm1, and Swi5) as zero-order ultrasensitive switches (Goldbeter and Koshland, 1981; Ferrell, 1996). We assume that each transcription factor (TF) exists as either an active or inactive form (let $\mathrm{F}=$ fraction in active form), and that transitions between the two forms are enzyme-catalyzed reactions following Michaelis-Menten kinetics,

$$
\frac{\mathrm{dF}}{\mathrm{dt}}=\frac{V_{\mathrm{a}}(1-\mathrm{F})}{J_{\mathrm{a}}+1-\mathrm{F}}-\frac{V_{\mathrm{i}} \mathrm{F}}{J_{\mathrm{i}}+\mathrm{F}}
$$

$V_{\mathrm{a}}$ and $V_{\mathrm{i}}$ are $V_{\max }$ values of the activating and inhibiting enzymes, and $J_{\mathrm{a}}$ and $J_{\mathrm{i}}$ are Michaelis constants (relative to the total concentrations of TF). If the transitions are fast enough $\left(V_{\mathrm{a}}\right.$ and $V_{\mathrm{i}}$ large enough) to keep each TF in its steady-state distribution, then

$$
\mathrm{F}=\mathrm{G}\left(V_{a}, V_{i}, J_{\mathrm{a}}, J_{\mathrm{i}}\right)=\frac{2 \gamma}{\beta+\sqrt{\beta^{2}-4 \alpha \gamma}}
$$

where $\alpha=V_{\mathrm{i}}-V_{\mathrm{a}}, \beta=V_{\mathrm{i}}-V_{\mathrm{a}}+V_{\mathrm{a}} J_{\mathrm{i}}+V_{\mathrm{i}} J_{\mathrm{a}}$, and $\gamma=V_{\mathrm{a}} J_{\mathrm{i}}$. Notice that $\mathrm{G}=1 / 2$ when $V_{\mathrm{a}} / V_{\mathrm{i}}=\left(2 J_{\mathrm{a}}+1\right) /\left(2 J_{\mathrm{i}}+1\right)$. If $J_{\mathrm{a}}$ and $J_{\mathrm{i}}$ are both $\ll 1$, then $50 \%$ of the TF is active when $V_{\mathrm{a}} / V_{\mathrm{i}}=$ 1. Moreover, Goldbeter and Koshland (1981) showed that G is a sharply sigmoidal function of $V_{\mathrm{a}} / V_{\mathrm{i}}$ if $J_{\mathrm{a}}$ and $J_{\mathrm{i}}$ are $\ll 1$.

In our model, this behavior shows up as a sharp activation of SBF by Cln3-dependent kinase, as the cell grows through a critical size. To calculate the size at which $[\mathrm{SBF}]=1 / 2$, we set $V_{\mathrm{a}}=V_{\mathrm{i}}$,

$$
\begin{array}{r}
k_{\mathrm{a}, \mathrm{sbf}}\left\{[\mathrm{Cln} 2]+\varepsilon_{\mathrm{sbf}, \mathrm{n} 3}\left([\mathrm{Cln} 3]^{*}+[\mathrm{Bck} 2]\right)+\varepsilon_{\mathrm{sbf}, \mathrm{b} 5}[\mathrm{Clb} 5]\right\}=k_{\mathrm{i}, \mathrm{sbf}}^{\prime} \\
+k_{\mathrm{i}, \mathrm{sbf}}^{\prime \prime}[\mathrm{Clb} 2]
\end{array}
$$

Noting that $[\mathrm{Cln} 2] \approx[\mathrm{Clb} 5] \approx[\mathrm{Clb} 2] \approx 0$ in $\mathrm{G} 1$, we find that $[\mathrm{SBF}]=1 / 2$ when

$k_{\mathrm{a}, \mathrm{sbf}} \cdot \varepsilon_{\mathrm{sbf,n} 3}\left([\mathrm{Cln} 3]_{\max } \frac{D_{n 3} \cdot \text { mass }}{J_{\mathrm{n} 3}+D_{n 3} \cdot \operatorname{mass}}+[\mathrm{Bck} 2]^{0} \cdot \operatorname{mass}\right)=k_{\mathrm{i}, \mathrm{sbf}}^{\prime}$

or, given the parameter values listed in Table 2,

$$
\frac{3 \cdot \text { mass }}{6+\text { mass }}+0.4 \cdot \text { mass }=1
$$

The solution of this quadratic equation is mass $\approx 1.2$. This is the critical size for SBF activation; in wild-type cells, all other events of Start occur in rapid succession after the cell activates SBF. (In the full model, SBF activates at a slightly smaller size, presumably because of the residual activities of the other kinases in G1, which we neglected in this calculation.) 


\section{ACKNOWLEDGMENTS}

We benefited greatly at various stages from conversations with Kim Nasmyth, Attila Toth, Jill Sible, Ray Deshaies, and Fred Cross and from the diligence of the anonymous referees. This work was supported by US National Science Foundation grants MCB-9600536 and DBI-9724085, National Science Foundation of Hungary grant T-022182, and Howard Hughes Medical Institute grant 75195542501.

\section{REFERENCES}

Alberts, B., Bray, D., Lewis, J., Raff, M., Roberts, K., and Watson, J.D. (1994). Molecular Biology of the Cell, 3rd ed., New York: Garland Publishing.

Alexandru, G., Zachariae, W., Schleiffer, A., and Nasmyth, K. (1999). Sister chromatid separation and chromosome reduplication are regulated by different mechanisms in response to spindle damage. EMBO J. 18, 2707-2721.

Amon, A. (1997). Regulation of B-type cyclin proteolysis by Cdc28associated kinases in budding yeast. EMBO J. 16, 2693-2702.

Amon, A. (1999). The spindle checkpoint. Curr. Opin. Genet. Dev. 9, $69-75$.

Amon, A., Irniger, S., and Nasmyth, K. (1994). Closing the cell cycle circle in yeast: G2 cyclin proteolysis initiated at mitosis persists until the activation of G1 cyclins in the next cycle. Cell 77, 1037-1050.

Amon, A., Surana, U., Muroff, I., and Nasmyth, K. (1992). Regulation of p34 ${ }^{\mathrm{CDC} 28}$ tyrosine phosphorylation is not required for entry into mitosis in S. cerevisiae. Nature 355, 368-371.

Amon, A., Tyers, M., Futcher, B., and Nasmyth, K. (1993). Mechanisms that help the yeast cell cycle clock tick: G2 cyclins transcriptionally activate G2 cyclins and repress G1 cyclins. Cell 74, 9931007.

Bai, C., Sen, P., Hofmann, K., Ma, L., Goebl, M., Harper, J.W., and Elledge, S.J. (1996). Skp1 connects cell cycle regulators to the ubiquitin proteolysis machinery through a novel motif, the F-box. Cell $86,263-274$.

Baroni, M.D., Monti, P., and Alberghina, L. (1994). Repression of growth-regulated G1 cyclin expression by cyclic AMP in budding yeast. Nature 371, 339-342.

Barral, Y., Jentsch, S., and Mann, C. (1995). G1 cyclin turnover and nutrient uptake are controlled by a common pathway in yeast. Genes Dev. 9, 399-409.

Biggins, S., and Murray, A.W. (1998). Sister chromatid cohesion in mitosis. Curr. Opin. Cell Biol. 10, 769-775.

Botchan, M. (1996). Coordinating DNA replication with cell division: current status of the licensing concept. Proc. Natl. Acad. Sci. USA 93, 9997-10000.

Carter, B.L.A. (1981). The control of cell division in Saccharomyces cerevisiae. In: The Cell Cycle, ed. P.C.L. John, Cambridge, UK: Cambridge University Press, 99-117.

Chang, F., and Herskowitz, I. (1990). Identification of a gene necessary for cell cycle arrest by a negative growth factor of yeast: Far1 is an inhibitor of G1 cyclin, CLN2. Cell 63, 999-1011.

Cho, R.J., et al. (1998). A genome-wide transcriptional analysis of the mitotic cell cycle. Mol. Cell 2, 65-73.

Ciosk, R., Zachariae, W., Michaelis, C., Shevchenko, A., Mann, M., and Nasmyth, K. (1998). An Esp1/Pds1 complex regulates loss of sister chromatid cohesion at the metaphase to anaphase transition in yeast. Cell 93, 1067-1076.
Cohen-Fix, O., and Koshland, D. (1999). Pds1p of budding yeast has dual roles: inhibition of anaphase initiation and regulation of mitotic exit. Genes Dev. 13, 1950-1959.

Cross, F.R. (1988). DAF1, a mutant gene affecting size control, pheromone arrest, and cell cycle kinetics of Saccharomyces cerevisiae. Mol. Cell. Biol. 8, 4675-4684.

Cross, F.R., and Tinkelenberg, A.H. (1991). A potential positive feedback loop controlling CLN1 and CLN2 gene expression at the start of the yeast cell cycle. Cell 65, 875-883.

Dahmann, C., Diffley, J.F.X., and Nasmyth, K. (1995). S-phase-promoting cyclin-dependent kinases prevent rereplication by inhibiting the transition of replication origins to a prereplicative state. Curr. Biol. 5, 1257-1269.

Dasso, M., and Newport, J.W. (1990). Completion of DNA replication is monitored by a feedback system that controls the initiation of mitosis in vitro: studies in Xenopus. Cell 61, 811-823.

Dawson, I.A., Roth, S., and Artavanis-Tsakonas, S. (1995). The Drosophila cell cycle gene fizzy is required for normal degradation of cyclins A and B during mitosis and has homology to the CDC2O gene of Saccharomyces cerevisiae. J. Cell Biol. 129, 725-737.

Descombes, P., and Nigg, E.A. (1998). The polo-like kinase Plx1 is required for $\mathrm{M}$ phase exit and destruction of mitotic regulators in Xenopus egg extracts. EMBO J. 17, 1328-1335.

Deshaies, R., Chau, V., and Kirschner, M. (1995). Ubiquitination of the G1 cyclin Cln2p by a Cdc34-dependent pathway. EMBO J. 14, 303-312.

Di Como, C.J., Chang, H., and Arndt, K.T. (1995). Activation of CLN1 and CLN2 G1 cyclin gene expression by BCK2. Mol. Cell. Biol. $15,1835-1846$

Dirick, L., Bohm, T., and Nasmyth, K. (1995). Roles and regulation of Cln/Cdc28 kinases at the start of the cell cycle of Saccharomyces cerevisiae. EMBO J. 14, 4803-4813.

Donovan, J.D., Toyn, J.H., Johnson, A.L., and Johnston, L.H. (1994). $\mathrm{p} 40^{\mathrm{SDB} 25}$, a putative Cdk inhibitor, has a role in M/G1 transition in Saccharomyces cerevisiae. Genes Dev. 8, 1640-1653.

Epstein, C.B., and Cross, F.R. (1992). CLB5: a novel B cyclin from budding yeast with a role in S phase. Genes Dev. 6, 1695-1706.

Epstein, C.B., and Cross, F.R. (1994). Genes that can bypass the CLN requirement for Saccharomyces cerevisiae cell cycle START. Mol. Cell. Biol. 14, 2041-2047.

Feldman, R.M.R., Correll, C.C., Kaplan, K., and Deshaies, R.J. (1997). A complex of Cdc4p, Skp1p and Cdc53/Cullin catalyzes ubiquitination of the phosphorylated CDK inhibitor Sic1p. Cell 91, 221-230.

Felix, M.-A., Labbe, J.-C., Doree, M., Hunt, T., and Karsenti, E. (1990). Triggering of cyclin degradation in interphase extracts of amphibian eggs by cdc2 kinase. Nature 346, 379-382.

Ferrell, J.E., Jr. (1996). Tripping the switch fantastic: how a protein kinase cascade can convert graded inputs into switch-like outputs. Trends Biochem. Sci. 21, 460-466.

Ferrell, J.E., Jr., Wu, M., Gerhart, J.C., and Martin, G.S. (1991). Cell cycle tyrosine phosphorylation of $\mathrm{p} 34^{\mathrm{cdc} 2}$ and a microtubule-associated protein kinase homolog in Xenopus oocytes and eggs. Mol. Cell. Biol. 11, 1965-1971.

Futcher, B. (1996). Cyclins and the wiring of the yeast cell cycle. Yeast 12, 1635-1646.

Goldbeter, A. (1991). A minimal cascade model for the mitotic oscillator involving cyclin and cdc2 kinase. Proc. Natl. Acad. Sci. USA $88,9107-9111$.

Goldbeter, A., and Koshland, D.E., Jr. (1981). An amplified sensitivity arising from covalent modification in biological systems. Proc. Natl. Acad. Sci. USA 78, 6840-6844. 
Hartwell, L.H., and Unger, M.W. (1977). Unequal division in Saccharomyces cerevisiae and its implications for the control of cell division. J. Cell Biol. 75, 422-435.

Hwang, L.H., Lau, L.F., Smith, D.L., Mistrot, C.A., Hardwick, K.G., Hwang, E.S., Amon, A., and Murray, A.W. (1998). Budding yeast Cdc20: a target of the spindle checkpoint. Science 279, 1041-1044.

Irniger, S., and Nasmyth, K. (1997). The anaphase-promoting complex is required in G1 arrested yeast cells to inhibit B-type cyclin accumulation and to prevent uncontrolled entry into S-phase. J. Cell Sci. $110,1523-1531$.

Irniger, S., Piatti, S., Michaelis, C., and Nasmyth, K. (1995). Genes involved in sister chromatid separation are needed for B-type cyclin proteolysis in budding yeast. Cell 81, 269-277.

Jackson, P.K. (1996). Cell cycle: cull and destroy. Curr. Biol. 6, 1209-1212.

Jaspersen, S.L., Charles, J.F., and Morgan, D.O. (1999). Inhibitory phosphorylation of the APC regulator Hct1 is controlled by the kinase Cdc28 and the phosphatase Cdc14. Curr. Biol. 11, 227-236.

Johnston, G.C., Ehrhardt, C.W., Lorincz, A., and Carter, B.L.A. (1979). Regulation of cell size in the yeast Saccharomyces cerevisiae. J. Bacteriol. 137, 1-5.

Johnston, G.C., Pringle, J.R., and Hartwell, L.H. (1977). Coordination of growth with cell division in the yeast Saccharomyces cerevisiae. Exp. Cell Res. 105, 79-98.

King, R.W., Deshaies, R.J., Peters, J.-M., and Kirschner, M.W. (1996). How proteolysis drives the cell cycle. Science 274, 1652-1659.

Knapp, D., Bhoite, L., Stillman, D.J., and Nasmyth, K. (1996). The transcription factor Swi5 regulates expression of the cyclin kinase inhibitor p40Sic1. Mol. Cell. Biol. 16, 5701-5707.

Koch, C., Moll, T., Neuberg, M., Ahorn, H., and Nasmyth, K. (1993). A role for the transcription factors Mbp1 and Swi4 in progression from G1 to S phase. Science 261, 1551-1557.

Koch, C., and Nasmyth, K. (1994). Cell cycle regulated transcription in yeast. Curr. Opin. Cell Biol. 6, 451-459.

Koch, C., Schleiffer, A., Ammerer, G., and Nasmyth, K. (1996). Switching transcription on and off during the yeast cell cycle: Cln/ Cdc28 kinases activate bound transcription factor SBF (Swi4/Swi6) at Start, whereas $\mathrm{Clb} / \mathrm{Cdc} 28$ kinases displace it from the promoter in G2. Genes Dev. 9, 129-141.

Kotani, S., Tugendreich, S., Fujii, M., Jorgensen, P.-M., Watanabe, N., Hoog, C., Hieter, P., and Todokoro, K. (1998). PKA and MPFactivated Polo-like kinase regulate anaphase-promoting complex activity and mitosis progression. Mol. Cell 1, 371-380.

Krek, W. (1998). Proteolysis and the G1-S transition: the SCF connection. Curr. Opin. Genet. Dev. 8, 36-42.

Lahav-Baratz, S., Sudakin, V., Ruderman, J.V., and Hershko, A. (1995). Reversible phosphorylation controls the activity of cyclosome-associated cyclin-ubiquitin ligase. Proc. Natl. Acad. Sci. USA 92, 9303-9307.

Lanker, S., Valdivieso, M.H., and Wittenberg, C. (1996). Rapid degradation of the $\mathrm{G} 1$ cyclin $\mathrm{Cln} 2$ induced by CDK-dependent phosphorylation. Science 271, 1597-1601.

Leatherwood, J. (1998). Emerging mechanisms of eukaryotic DNA replication initiation. Curr. Opin. Cell Biol. 10, 742-748.

Li, F.N., and Johnston, M. (1997). Grr1 of Saccharomyces cerevisiae is connected to the ubiquitin proteolysis machinery through Skp1: coupling glucose sensing to gene expression and the cell cycle. EMBO J. 16, 5629-5638.

Lim, H.H., Goh, P.-Y., and Surana, U. (1998). Cdc20 is essential for the cyclosome-mediated proteolysis of both Pds1 and Clb2 during M phase in budding yeast. Curr. Biol. 8, 231-234.
Lorca, T., Castro, A., Martinez, A.M., Vigneron, S., Morin, N., Sigrist, S., Lehner, C., Doree, M., and Labbe, J.C. (1998). Fizzy is required for activation of the APC/cyclosome in Xenopus egg extract. EMBO J. 17, 3565-3575.

Lord, P.G., and Wheals, A.E. (1980). Asymmetrical division of Saccharomyces cerevisiae. J. Bacteriol. 142, 808-818.

Maher, M., Cong, F., Kindelberger, D., Nasmyth, K., and Dalton, S. (1995). Cell cycle-regulated transcription of CLB2 gene is dependent on $\mathrm{Mcm} 1$ and a ternary complex factor. Mol. Cell. Biol. 15, 31293137.

Mendenhall, M.D., and Hodge, A.E. (1998). Regulation of Cdc28 cyclin-dependent protein kinase activity during the cell cycle of the yeast Saccharomyces cerevisiae. Microbiol. Mol. Biol. Rev. 62, 11911243.

Murray, A., and Hunt, T. (1993). The Cell Cycle: An Introduction, New York: W.H. Freeman.

Nash, R., Tokiwa, G., Anand, S., Erickson, K., and Futcher, A.B. (1988). The WHI1 ${ }^{+}$gene of Saccharomyces cerevisiae tethers cell division to cell size and is a cyclin homolog. EMBO J. 7, 4335-4346.

Nasmyth, K. (1993). Control of the yeast cell cycle by Cdc28 protein kinase. Curr. Opin. Cell Biol. 5, 166-179.

Nasmyth, K. (1995). Evolution of the cell cycle. Philos. Trans. R. Soc. Lond. B 349, 271-281.

Nasmyth, K. (1996). At the heart of the budding yeast cell cycle. Trends Genet. 12, 405-412.

Nasmyth, K. (1999). Separating sister chromatids. Trends Biochem. Sci. $24,98-104$.

Nasmyth, K., Adolf, G., Lydall, D., and Seddon, A. (1990). The identification of a second cell cycle control on the $\mathrm{HO}$ promotor in yeast: cell cycle regulator of SWI5 nuclear entry. Cell 62, 631-647.

Nasmyth, K., and Dirick, L. (1991). The role of SWI4 and SWI6 in the activity of G1 cyclins in yeast. Cell 66, 995-1013.

Novak, B., Csikasz-Nagy, A., Gyorffy, B., Nasmyth, K., and Tyson, J.J. (1998). Model scenarios for evolution of the eukaryotic cell cycle. Philos. Trans. R. Soc. Lond. B 353, 2063-2076.

Novak, B., Toth, A., Csikasz-Nagy, A., Gyorffy, B., Tyson, J.J., and Nasmyth, K. (1999). Finishing the cell cycle. J. Theor. Biol. 199, 223-233.

Novak, B., and Tyson, J.J. (1993). Numerical analysis of a comprehensive model of M-phase control in Xenopus oocyte extracts and intact embryos. J. Cell Sci. 106, 1153-1168.

Novak, B., and Tyson, J.J. (1995). Quantitative analysis of a molecular model of mitotic control in fission yeast. J. Theor. Biol. 173, 283-305.

Novak, B., and Tyson, J.J. (1997). Modeling the control of DNA replication in fission yeast. Proc. Natl. Acad. Sci. USA 94, 9147-9152.

Nugroho, T.T., and Mendenhall, M.D. (1994). An inhibitor of yeast cyclin-dependent protein kinase plays an important role in ensuring the genomic integrity of daughter cells. Mol. Cell. Biol. 14, 33203328.

Peter, M., and Herskowitz, I. (1994). Direct inhibition of the yeast cyclin-dependent kinase Cdc28-Cln by Far1. Science 265, 1228-1231.

Peters, J.-M. (1998). SCF and APC: the yin and yang of cell cycle regulated proteolysis. Curr. Opin. Cell Biol. 10, 759-768.

Peters, J.-M., King, R.W., Hoog, C., and Kirschner, M.W. (1996). Identification of BimE as a subunit of the anaphase-promoting complex. Science 274, 1199-1201.

Polymenis, M., and Schmidt, E.V. (1997). Coupling of cell division to cell growth by translational control of the G1 cyclin CLN3 in yeast. Genes Dev. 11, 2522-2531. 
Polymenis, M., and Schmidt, E.V. (1999). Coordination of cell growth with cell division. Curr. Opin. Genet. Dev. 9, 76-80.

Posas, F., Takekawa, M., and Saito, H. (1998). Signal transduction by MAP kinase cascade in budding yeast. Curr. Opin. Microbiol. 1, 175-182.

Prinz, S., Hwang, E.S., Visintin, R., and Amon, A. (1998). The regulation of Cdc20 proteolysis reveals a role for the APC components $\mathrm{Cdc} 23$ and $\mathrm{Cdc} 27$ during $\mathrm{S}$ phase and early mitosis. Curr. Biol. $8,750-760$.

Richardson, H., Lew, D.J., Henze, M., Sugimoto, K., and Reed, S.I. (1992). Cyclin-B homologs in Saccharomyces cerevisiae function in S phase and in G2. Genes Dev. 6, 2021-2034.

Richardson, H.E., Wittenberg, C., Cross, F., and Reed, S.I. (1989). An essential G1 function for cyclin-like proteins in yeast. Cell 59, 11271133.

Salama, S.R., Hendricks, K.B., and Thorner, J. (1994). G1 cyclin degradation: the PEST motif of yeast $C \ln 2$ is necessary, but not sufficient, for rapid protein turnover. Mol. Cell. Biol. 14, 7953-7966.

Schneider, B.L., Yang, Q.-H., and Futcher, B. (1996). Linkage of replication to Start by the Cdk inhibitor Sic1. Science 272, 560-562.

Schwab, M., Lutum, A.S., and Seufert, W. (1997). Yeast Hct1 is a regulator of Clb2 cyclin proteolysis. Cell 90, 683-693.

Schwob, E., Bohm, T., Mendenhall, M.D., and Nasmyth, K. (1994). The B-type cyclin kinase inhibitor p40 ${ }^{\text {sic } 1}$ controls the G1 to S transition in S. cerevisiae. Cell 79, 233-244.

Schwob, E., and Nasmyth, K. (1993). CLB5 and CLB6, a new pair of B cyclins involved in DNA replication in Saccharomyces cerevisiae. Genes Dev. 7, 1160-1175.

Seufert, W., Futcher, B., and Jentsch, S. (1995). Role of a ubiquitinconjugating enzyme in degradation of S- and M-phase cyclins. Nature 373, 78-81.

Shirayama, M., Zachariae, W., Ciosk, R., and Nasmyth, K. (1998). The Polo-like kinase Cdc5p and the WD-repeat protein Cdc20p/ fizzy are regulators and substrates of the anaphase promoting complex in Saccharomyces cerevisiae. EMBO J. 17, 1336-1349.

Shou, W., and Dunphy, W.G. (1996). Cell cycle control by Xenopus p28Kix1, a developmentally regulated inhibitor of cyclin-dependent kinases. Mol. Biol. Cell 7, 457-469.

Shou, W., Seol, J.H., Shevchenko, A., Baskerville, C., Moazed, D., Chen, Z.W.S., Jang, J., Shevchenko, A., Charbonneau, H., and Deshaies, R.J. (1999). Exit from mitosis is triggered by Tem1-dependent release of the protein phosphatase Cdc14 from nucleolar RENT complex. Cell 97, 233-244.

Sigrist, S., Jacobs, H., Stratmann, R., and Lehner, C.F. (1995). Exit from mitosis is regulated by Drosophila fizzy and the sequential destruction of cyclins A, B, and B3. EMBO J. 14, 4827-4838.

Skowyra, D., Craig, K.L., Tyers, M., Elledge, S.J., and Harper, J.W. (1997). F-box proteins are receptors that recurit phosphorylated substrates to the SCF ubiquitin-ligase complex. Cell 91, 209-219.

Smythe, C., and Newport, J.W. (1992). Coupling of mitosis to the completion of $\mathrm{S}$ phase in Xenopus occurs via modulation of the tyrosine kinase that phosphorylates p34 ${ }^{\text {cdc2 }}$. Cell 68, 787-797.

Sorger, P.K., and Murray, A.W. (1992). S-phase feedback control in budding yeast independent of tyrosine phosphorylation of p34 cdc28. Nature 355, 365-368.

Spellman, P.T., Sherlock, G., Zhang, M.Q., Iyer, V.R., Anders, K., Eisen, M.B., Brown, P.O., Botstein, D., and Futcher, B. (1998). Comprehensive identification of cell cycle-regulated genes of the yeast Saccharomyces cerevisiae by microarray hybridization. Mol. Biol. Cell 9, 3273-3297.
Stuart, D., and Wittenberg, C. (1995). CLN3, not positive feedback, determines the timing of CLN2 transcription in cycling cells. Genes Dev. 9, 2780-2794.

Su, J.-Y., Rempel, R.E., Erikson, E., and Maller, J.L. (1995). Cloning and characterization of the Xenopus cyclin-dependent kinase inhibitor p27 ${ }^{\text {Xic1 }}$. Proc. Natl. Acad. Sci. USA 92, 10187-10191.

Sudakin, V., Ganoth, D., Dahan, A., Heller, H., Hershko, J., Luca, F.C., Ruderman, J.V., and Hershko, A. (1995). The cyclosome, a large complex containing cyclin-selective ubiquitin ligase activity, targets cyclins for destruction at the end of mitosis. Mol. Biol. Cell 6 , 185-197.

Surana, U., Amon, A., Dowzer, C., McGrew, J., Byers, B., and Nasmyth, K. (1993). Destruction of the CDC28/CLB mitotic kinase is not required for the metaphase to anaphase transition in budding yeast. EMBO J. 12, 1969-1978.

Surana, U., Robitsch, H., Price, C., Schuster, T., Fitch, I., Futcher, A.B., and Nasmyth, K. (1991). The role of CDC28 and cyclins during mitosis in the budding yeast $S$. cerevisiae. Cell 65, 145-161.

Taylor, S.S. (1999). Chromosome segregation: dual control ensures fidelity. Curr. Biol. 9, R562-R564.

Tinker-Kulberg, R.L., and Morgan, D.O. (1999). Pds1 and Esp1 control both anaphase and mitotic exit in normal cells and after DNA damage. Genes Dev. 13, 1936-1949.

Tinoco, I., Jr., Sauer, K., and Wang, J.C. (1978). Physical Chemistry. Principles and Applications in Biological Sciences, 3rd ed., Upper Saddle River, NJ: Prentice Hall.

Tokiwa, G., Tyers, M., Volpe, T., and Futcher, B. (1994). Inhibition of G1 cyclin activity by the Ras/cAMP pathway in yeast. Nature 371, 342-345.

Tyers, M. (1996). The cyclin-dependent kinase inhibitor p40sic1 imposes the requirement for Cln G1 cyclin function at Start. Proc. Natl. Acad. Sci. USA 93, 7772-7776.

Tyers, M., Tokiwa, G., and Futcher, B. (1993). Comparison of the Saccharomyces cerevisae G1 cyclins: $\mathrm{Cln} 3$ may be an upstream activator of $C \ln 1, C \ln 2$ and other cyclins. EMBO J. 12, 1955-1968.

Tyson, J.J., Chen, K.C., and Novak, B. (1997). The eukaryotic cell cycle: molecules, mechanisms and mathematical models. In: Case Studies in Mathematical Modeling: Ecology, Physiology and Cell Biology, ed. H.G. Othmer, F.R. Adler, M.A. Lewis, and J.C. Dallon, Upper Saddle River, NJ: Prentice Hall, 127-147.

Tyson, J.J., Novak, B., Chen, K.C., and Val, J. (1995). Checkpoints in the cell cycle from a modeler's perspective. In: Progress in Cell Cycle Research, ed. L. Meijer, S. Guidet, and H.Y.L. Tung, New York: Plenum Press, 1-8.

Tyson, J.J., Novak, B., Odell, G.M., Chen, K., and Thron, C.D. (1996). Chemical kinetic theory as a tool for understanding the regulation of M-phase promoting factor in the cell cycle. Trends Biochem. Sci. 21, 89-96.

Verma, R., Annan, R.S., Huddleston, M.J., Carr, S.A., Reynard, G., and Deshaies, R.J. (1997). Phosphorylation of Sic1p by G1 Cdk required for its degradation and entry into S phase. Science 278, $455-460$.

Visintin, R., Craig, K., Hwang, E.S., Prinz, S., Tyers, M., and Amon, A. (1998). The phosphatase Cdc14 triggers mitotic exit by reversal of Cdk-dependent phosphorylation. Mol. Cell 2, 709-718.

Visintin, R., Hwang, E.S., and Amon, A. (1999). Cfi1 prevents premature exit from mitosis by anchoring Cdc14 phosphatase in the nucleolus. Nature 398, 818-823.

Visintin, R., Prinz, S., and Amon, A. (1997). CDC20 and CDH1: a family of substrate-specific activators of APC-dependent proteolysis. Science 278, 460-463.

Willems, A.R., Lanker, S., Patton, E.E., Craig, K.L., Nason, T.F., Mathias, N., Kobayashi, R., Wittenberg, C., and Tyers, M. (1996). 
Cdc53 targets phosphorylated G1 cyclins for degradation by the ubiquitin proteolytic pathway. Cell 86, 453-463.

Wittenberg, C., and Reed, S.I. (1996). Plugging it in: signaling circuits and the yeast cell cycle. Curr. Opin. Cell Biol. 6, 223-230.

Wittenberg, C., Sugimoto, K., and Reed, S.I. (1990). G1-specific cyclins of $S$. cerevisiae: cell cycle periodicity, regulation by mating pheromone, and association with p34CDC28 protein kinase. Cell 62, 225-237.

Wuarin, J., and Nurse, P. (1996). Regulating $S$ phase: CDKs, licensing and proteolysis. Cell 85, 785-787.

Yaglom, J., Linskens, H.K., Rubin, D.M., Futcher, B., and Finley, D. (1995). p34Cdc28-mediated control of Cln3 cyclin degradation. Mol. Cell. Biol. 15, 731-741.
Yamamoto, A., Guacci, V., and Koshland, D. (1996). Pds1p, an inhibitor of anaphase in budding yeast, plays a critical role in the APC and checkpoint pathway(s). J. Cell Biol. 133, 99-110.

Zachariae, W., and Nasmyth, K. (1999). Whose end is destruction: cell division and the anaphase-promoting complex. Genes Dev. 13, 2039-2058.

Zachariae, W., Schwab, M., Nasmyth, K., and Seufert, W. (1998). Control of cyclin ubiquitination by CDK-regulated binding of Hct1 to the anaphase promoting complex. Science 282, 1721-1724.

Zachariae, W., Shin, T.H., Galova, M., Obermaier, B., and Nasmyth, K. (1996). Identification of subunits of the anaphasepromoting complex of Saccharomyces cerevisiae. Science 274, 12011204. 